\title{
Tob2 phosphorylation regulates global mRNA turnover to reshape transcriptome and impact cell proliferation
}

\author{
CHYI-YING A. CHEN, KRISTA STROUZ, KAI-LIEH HUANG, ${ }^{1}$ and ANN-BIN SHYU \\ Department of Biochemistry and Molecular Biology, McGovern Medical School, The University of Texas Health Science Center at Houston, \\ Houston, Texas 77030, USA
}

\begin{abstract}
Tob2, an anti-proliferative protein, promotes deadenylation through recruiting Caf1 deadenylase to the mRNA poly(A) tail by simultaneously interacting with both Caf1 and poly(A)-binding protein (PABP). Previously, we found that changes in Tob2 phosphorylation can alter its PABP-binding ability and deadenylation-promoting function. However, it remained unknown regarding the relevant kinase(s). Moreover, it was unclear whether Tob2 phosphorylation modulates the transcriptome and whether the phosphorylation is linked to Tob2's anti-proliferative function. In this study, we found that c-Jun amino-terminal kinase (JNK) increases phosphorylation of Tob2 at many Ser/Thr sites in the intrinsically disordered region (IDR) that contains two separate PABP-interacting PAM2 motifs. JNK-induced phosphorylation or phosphomimetic mutations at these sites weaken the Tob2-PABP interaction. In contrast, JNK-independent phosphorylation of Tob2 at serine 254 (S254) greatly enhances Tob2 interaction with PABP and its ability to promote deadenylation. We discovered that both PAM2 motifs are required for Tob2 to display these features. Combining mass spectrometry analysis, poly(A) size-distribution profiling, transcriptome-wide mRNA turnover analyses, and cell proliferation assays, we found that the phosphomimetic mutation at S254 (S254D) enhances Tob2's association with PABP, leading to accelerated deadenylation and decay of mRNAs globally. Moreover, the Tob2-S254D mutant accelerates the decay of many transcripts coding for cell cycle related proteins and enhances anti-proliferation function. Our findings reveal a novel mechanism by which Ccr4-Not complex is recruited by Tob2 to the mRNA 3' poly(A)-PABP complex in a phosphorylation dependent manner to promote rapid deadenylation and decay across the transcriptome, eliciting transcriptome reprogramming and suppressed cell proliferation.
\end{abstract}

Keywords: mRNA turnover; deadenylation; transcriptome programming; PABP interaction; Ccr4-Not complex; phosphorylation

\section{INTRODUCTION}

The degradation of cytoplasmic mRNA transcripts plays an essential role in modulation of gene expression and quality control of mRNA biogenesis (Garneau et al. 2007; Shyu et al. 2008; Reznik and Lykke-Andersen 2010). Deadenylation, the shortening of mRNA $3^{\prime}$ poly $(A)$ tail, is an initiating and rate-limiting step of $m R N A$ degradation (Cao and Parker 2001; Chen and Shyu 2011). Deadenylation itself begins by recruitment of the Pan2-Pan3 and the Ccr4-Not deadenylase complexes to the targeted mRNA (Shyu et al. 2008; Chen and Shyu 2011; Du et al. 2016). Much has been learned about the important role of deadenylation in reprogramming the maternal transcriptome during oocyte maturation and early embryogenesis (e.g., see Weill et al. 2012; Lim et al. 2016; Mishima and Tomari

\footnotetext{
${ }^{1}$ Present address: Department of Biochemistry and Molecular Biology, University of Texas Medical Branch at Galveston, Galveston, TX 77550, USA

Corresponding author: Ann-Bin.Shyu@uth.tmc.edu

Article is online at http://www.rnajournal.org/cgi/doi/10.1261/rna. 073528.119.
}

2016; Morgan et al. 2017). However, the transcriptomes of mammalian somatic cells also undergo reprogramming and it is unclear what role deadenylation may play in this context.

Recent studies have shed light on this important issue. For example, histone acetyltransferases p300 and CBP were shown to mediate acetylation of Caf1a (CNOT7) deadenylase, leading to accelerated mRNA degradation at the transcriptome level during adipocyte differentiation (Sharma et al. 2016). Additionally, we found that cell proliferation can be regulated by altering expression of two isoforms of Pan3, which profoundly impacts deadenylation and mRNA turnover across the transcriptome (Chen et al. 2017). Earlier, we showed that the interaction of Tob proteins with PABP that promotes deadenylation is linked to

\footnotetext{
(c) 2020 Chen et al. This article is distributed exclusively by the RNA Society for the first 12 months after the full-issue publication date (see http://rnajournal.cshlp.org/site/misc/terms.xhtml). After 12 months, it is available under a Creative Commons License (Attribution-NonCommercial 4.0 International), as described at http:// creativecommons.org/licenses/by-nc/4.0/.
} 
Tob's anti-proliferative function (Ezzeddine et al. 2012; Huang et al. 2013). This raised an important question as to whether Tob proteins exert their anti-proliferative function by reprogramming the transcriptome via promoting global mRNA deadenylation and decay.

The human Tob proteins (Tob1 and Tob2) are encoded by paralogous genes belonging to the mammalian BTG/ Tob family of anti-proliferative factors that regulate cell growth in a variety of cell types (Mauxion et al. 2009; Winkler 2010). The Tob proteins have a highly conserved amino-terminal domain, the BTG domain, which interacts strongly with Caf1 deadenylase (Miyasaka et al. 2008; Mauxion et al. 2009; Winkler 2010), a catalytic subunit of the large Ccr4-Not complex (Collart 2016). Tob proteins are unique among the BTG family members in that they can bind PABP (Okochi et al. 2005) via two separate PABP-interacting motifs (PAM2 motifs) present in a long carboxy-terminal domain with an extensive intrinsically disordered region (IDR) (Albrecht and Lengauer 2004; Huang et al. 2013). The eukaryotic translation termination factor 3 (eRF3) contains two overlapping PAM2 motifs that bind PABP in a mutually exclusive manner (Hoshino 2012; Osawa et al. 2012), and all other known PAM2-containing proteins have only one PAM2 motif(Albrecht and Lengauer 2004; Kozlov et al. 2010). It's unclear as to whether both PAM2 motifs are required for Tob proteins to interact with PABP.

The anti-proliferative function of BTG/Tob proteins is closely linked to their ability to enhance deadenylation and requires functional Caf1 deadenylases (Mauxion et al. 2008; Doidge et al. 2012; Ezzeddine et al. 2012). The simultaneous interaction of Tob proteins with PABP and Caf1 accelerate deadenylation without significantly changing the overall decay rate of the deadenylated RNA body (Ezzeddine et al. 2007, 2012). Mutating the two PAM2 motifs or introducing multiple phosphomimetic mutations to the carboxy-terminal IDR of Tob2 weakens its interaction with PABP and also compromises both its ability to promote transcript deadenylation and its anti-proliferative function (Ezzeddine et al. 2012; Huang et al. 2013). Collectively, these findings suggest that the anti-proliferative function of Tob proteins is controlled by one or more signaling pathways that change the proteins' phosphorylation state, altering their interactions with PABP and thus their ability to promote deadenylation.

In this study, we conducted kinase screening and phosphosite mapping to identify the sites of phosphorylation in Tob2 and the kinases involved; used mass-spectrometry analysis to reveal potential recruitment of Ccr4-Not complex by Tob2; and used transcriptome-based approaches to assess the impact of Tob2 and S254D phosphomimetic mutant on global mRNA deadenylation and decay. The results support the notion that Tob2 promotes global mRNA turnover in a signaling-dependent manner, which represents a mode of cytoplasmic mRNA clearance that helps to reprogram the transcriptome during mammalian somatic cell growth and differentiation.

\section{RESULTS}

\section{JNK-induced Tob2 phosphorylation down-regulates Tob2-PABP interaction.}

Previously, we found that calyculin A, a potent phosphatase inhibitor (Suganuma et al. 1990), increases the phosphorylation level of Tob2 and reduces Tob2's PABPbinding ability (Huang et al. 2013). To gain further insights into mechanistic connections between Tob2's phosphorylation level and its functions, we set out to identify kinase(s) involved in the reduction of Tob2's PABP-binding ability. We reasoned that treating Tob2-expressing cells with an inhibitor selective for a relevant kinase prior to calyculin A "trapping" would decrease the calyculin A-induced phosphorylation of Tob2. Combining this approach with western blot analysis, we tested 10 different kinase inhibitors and found that c-Jun amino-terminal kinase (JNK) inhibitor diminishes the calyculin A-induced phosphorylation of Tob2 (Supplemental Fig. S1A). The results suggest an involvement of the JNK pathway in increasing the Tob2 phosphorylation and decreasing Tob2-PABP interaction.

We then tested if expression of a constitutively active JNK1 (CA-JNK1) would increase the Tob2 phosphorylation level and reduce the Tob2-PABP interaction. We performed a coimmunoprecipitation (co-IP) western blot analysis to compare Tob-PABP interactions in the cells with or without CA-JNK1 expression. To help evaluate the change in Tob2-PABP interaction, we developed a Relative PABP-binding Index (RPBI) with the RPBI value for the interaction between WT Tob2 and PABP in the control condition set as 1 (Supplemental Fig. S1B). To assess the linearity of response of the western blot detection, we did a diagnostic co-IP western blot analysis using increasing amounts $(1 / 4 \times$ to $4 \times)$ of lysates prepared from human 293T cells transfected with plasmid DNA encoding wild type (WT) Tob2-V5 along with or without the plasmid DNA encoding CA-JNK1 mutant (Supplemental Fig. S1C; Lei et al. 2002). The results showed that expression of CAJNK1 induced the production of hyper-phosphorylated Tob2 proteins, leading to a pattern with multiple bands. In contrast, the migration or banding pattern of PABP or Caf1 was not changed. Moreover, the expression of CAJNK1 diminishes Tob2's interaction with PABP by $\sim 2.5$ fold under all five co-IP reactions tested, with an average of RPBI values of $0.40 \pm 0.03$. The small standard deviation indicates that our co-IP protocol properly captured the association of PABP with Tob2 in a way proportional to the amount of Tob2 proteins present in the lysates prepared from cells with or without JNK activation and that the linearity of response of the western blot detection covers up to an order of magnitude $(1 / 4 \times$ to $4 \times)$ of Tob2 protein level. 
We then test whether expression of CA-JNK1 also increases the Tob2 phosphorylation level and reduces the Tob2-PABP interaction in human U2OS cells. Western blot analysis shows that in cells expressing of CAJNK1, an increased phosphorylation level of Tob2 was observed, accompanied by a decreased amount of PABP pulled down by Tob2 (Fig. 1A, RPBI $=0.30 \pm 0.05$ ). In contrast, changes in Tob2 phosphorylation level caused little change in the ability of Tob2 to pull down Caf1 (Fig. 1A). Similar results were also observed using mouse NIH3T3 cells (Supplemental Fig. S2A). In addition, expression of a JNK1 dominant-negative mutant (JNK1-DN) to block potential background activity of JNK has little effect on Tob2's interaction with PABP (Supplemental Fig. S2B). Together, these results indicate that JNK-induced phosphorylation of Tob2 diminishes the protein's PABPbinding ability.

To further substantiate the above findings, we tested the effect of a JNK activator, anisomycin (lordanov et al. 1997), on the phosphorylation and PABP-binding ability of Tob2 (Fig. 1B). Western blot analysis readily detected phospho-JNKs (p-JNKs) in U2OS cells treated with anisomycin (Fig. 1B), confirming activation of JNKs. The co-IP western blotting results show an increase in Tob2 phosphorylation in anisomycin-treated cells. Concomitantly, the ability of Tob2 to pull down PABP was significantly decreased in anisomycintreated cells with a RPBI of $0.70 \pm 0.09$ $(P<0.002)$, while Tob2 pull down of Caf1 was not altered (Fig. 1B). Collectively, we conclude that JNK-mediated phosphorylation impairs the interaction between Tob2 and PABP.

\section{JNK-independent phosphorylation of S254 in the second PAM2 motif of Tob2 increases Tob2 interaction with PABP}

We used mass spectrometry (mass spec)-based phosphosite-mapping
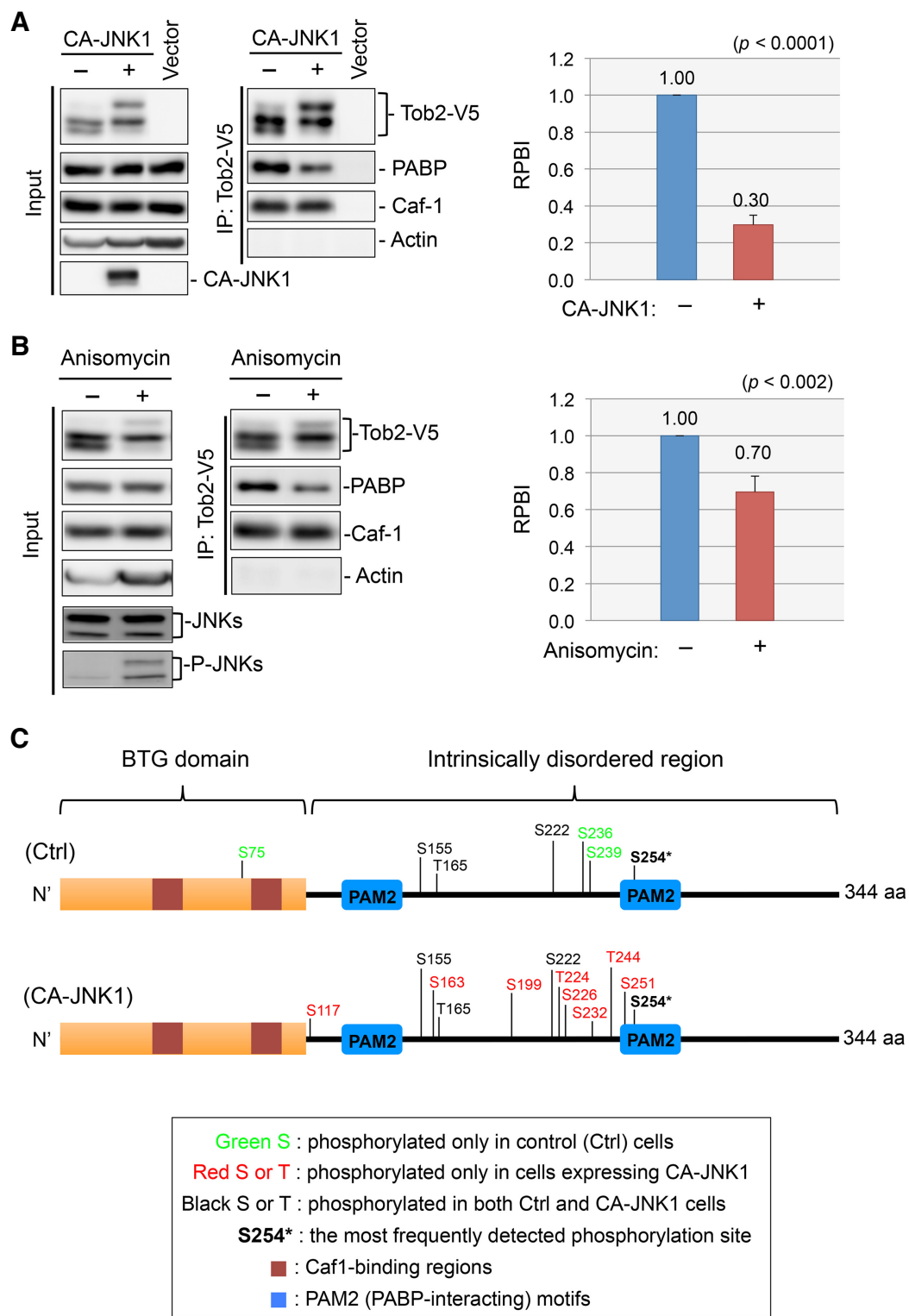

FIGURE 1. JNK activation weakens Tob2-PABP interaction through phosphorylating multiple serine and threonine residues in the intrinsically disordered region (IDR) of Tob2. (A) Co-IP western blot analysis showing that expression of constitutively active JNK1 (CA-JNK1) in U2OS cells increased phosphorylation of Tob2-V5 and diminished its interaction with PABP. In contrast, Tob2 interaction with Caf1 deadenylase was not affected by CA-JNK1 expression. Transfection with empty vector and western blot probed for actin served as negative controls. Bar graph shows the relative changes of Tob2-PABP interactions in the presence of CA-JNK1 expression using the calculated relative PABP-binding index (RPBI) values as described in Supplemental Figure S1B. The RPBI for Tob2-PABP interaction in the absence of CA-JNK1 was set as 1. All data represent the normalized mean $\pm S D(n=4)$. (B) Co-IP western blot analysis showing that anisomycin, a JNK agonist, increased Tob2-V5 phosphorylation and weakened its interaction with PABP. JNK activation was verified by detection of $p$-JNK by the phospho-SAPK/JNK (Thr183/Tyr185) antibody. Actin served as a negative control. Bar graph shows the RPBI values for Tob2-PABP interactions in the cells with or without anisomycin treatment. The RPBI for Tob2-PABP interaction in the cells without anisomycin treatment was set as 1. All data represent the normalized mean $\pm \mathrm{SD}(n=3)$. $P$ values were obtained from $t$-test. Cell extracts for IP experiments were prepared from U2OS cells transiently transfected with plasmids encoding the indicated proteins. $(C)$ Schematic diagram of the Tob2 domain structure and phosphorylation sites. Tob2-V5 immunoprecipitates were prepared from U2OS cells without (Ctrl) or with CA-JNK1 expression for mass-spectrometry mapping of phosphorylated sites in Tob2 (Supplemental Table S1). 
using U2OS cells expressing Tob2-V5 in the presence of CA-JNK1 or an empty vector (control) to identify Tob2 residues whose phosphorylation affects the protein's PABP-binding activity (Fig. 1C). Consistent with our previous observations (Huang et al. 2013), most phosphorylation of Tob2 occurs in the intrinsically disordered region (IDR) that harbors the two PABP-interacting PAM2 motifs (Fig. 1C; Supplemental Table S1). As expected, more phosphorylated residues were detected in cells expressing CA-JNK1 than in control cells (Fig. 1C). Twelve Ser (S)/Thr (T) residues were found to be phosphorylated in cells expressing CA-JNK1. Four of these phosphorylated residues were also found in control cells (Fig. 1C, black); the remaining eight residues were phosphorylated only in CA-JNK1 cells (Fig. 1C, red).

We then introduced one or two phosphomimetic mutations [Ser (S)/Thr (T) $\rightarrow$ Asp (D)/Glu (E)] at a time in the twelve sites and assessed the effects on Tob2's PABP-binding activity by co-IP western blot experiments (Supplemental Fig. S3). The results revealed that phosphomimetic mutation of S254, located at the fourth position in the second PAM2 motif of human Tob2 (Supplemental Fig. S4), was unique in that it greatly increased the pull down of PABP compared to WT Tob2 (Fig. 2A; Supplemental Fig. S3). All other phosphomimetic mutations tested either modestly reduced the Tob2-PABP interaction or had no effect (Supplemental Fig. S3). These observations (Figs. 1C, 2A; Supplemental Fig. S3) reveal an unexpected, JNK-independent phosphorylation at S254 that increases Tob2-PABP interaction, an effect opposing that caused by JNK-induced hyperphosphorylation.

When all of the phosphorylation sites detected in the presence of CA-JNK1 except S254 were simultaneously converted to Asp or Glu residues, the resulting mutant (Tob2-PM11) pulled down much less PABP than did WT Tob2 (Fig. 2B), confirming again the negative effect of JNK-induced phosphorylation on Tob2-PABP interaction (Fig. 1A,B). Thus, there are at least two distinct mechanisms for regulating the interaction between Tob2 and PABP through selective phosphorylation. JNK-dependent phosphorylation of several Ser/Thr residues in the IDR of Tob2 decreases its PABP-binding (Fig. 1), whereas the JNK-independent phosphorylation of Tob2 at S254 increases its PABP-binding activity (Fig. 2A).

In light of the finding that S254D increases Tob2's PABPbinding activity (Fig. 2A), we analyzed the sequences of other human PAM2-containing proteins. Among the human PAM2-containing proteins identified thus far, Tob1 and Tob2 are the only ones that carry two separate PAM2 motifs (Albrecht and Lengauer 2004; Huang et al. 2013; Xie et al. 2014). A sequence alignment (Supplemental Fig. S4) shows that only the second PAM2 motif of Tob1 and the sole PAM2 motif of PAIP1 also have a serine residue at the fourth position of the PAM2 motif (Ser268 of Tob1 and Ser129 of PAIP1). To test wheth- er phosphorylation of these serine residues affects the interaction of Tob1 or PAIP1 with PABP, we created the phosphomimetic mutants Tob1-S268D and PAIP1S129D for co-IP western blot analysis. The results show that like Tob2-S254D mutant, Tob1-S268D mutant also pulled down significantly more PABP than WT Tob1 (Fig. 2C). In contrast, PAIP1-S129D had no significant effect on PAIP-PABP interaction (Fig. 2D). These results reveal a novel, regulatory action on PABP-binding by phosphorylation of the serine residue at the fourth position in the second PAM2 motif of the Tob proteins.

\section{Both PAM2 motifs of Tob2 are critical for S254D- enhanced Tob2-PABP interaction}

The present finding that the PABP-interacting ability of Tob2 can be enhanced by phosphorylation at a single site (S254) in its second PAM2 motif (Fig. 2A) raises a question as to whether the interaction of Tob2 with PABP or the enhancing effect of phosphorylation at S254 requires both PAM2 motifs. To address the question, we mutated the conserved phenylalanine residue in the first, second, or both PAM2 motifs to alanine residue to create Tob2F140A, Tob2-260A, or Tob2-FF mutant, respectively. The results of co-IP western blot analyses (Fig. 2E) confirm our previous observation that Tob2-FF lost the ability to pull down PABP (Ezzeddine et al. 2007). Moreover, disruption of either PAM2 motif dramatically decreased the PABP-binding activity of Tob2 with a combined RPBI value of 0.52, which is only half of that of WT Tob2 (Fig. 2E), indicative of a synergism between the two PAM2 motifs to achieve full PABP-binding.

To see if either one or both of the two PAM2 motifs are required for the enhancing effect of S254D mutation on the Tob2-PABP interaction, we introduced F140A, F260A, or both mutations into Tob2-S254D mutant to create the S254D/F140A, S254D/F260A, and S254D/FF mutants, respectively. Co-IP western blot analyses (Fig. 2F) show that when either one or both of PAM2 motifs were disrupted, S254D mutation no longer enhanced PABPbinding. Together, these results indicate that the two PAM2 motifs function synergistically to constitute an integrated unit required for effective Tob2-PABP interaction, and also for displaying the enhancing effect of S254 phosphorylation.

\section{Interplay between JNK-induced and JNK-independent phosphorylation in modulation of Tob2's PABP-binding activity}

To assess how the combination of JNK-induced and JNKindependent phosphorylation of Tob2 would affect its PABP-binding activity, we introduced PM11 mutations (mimics JNK-induced phosphorylation) into the S254D mutant (mimics JNK-independent phosphorylation) to 
A

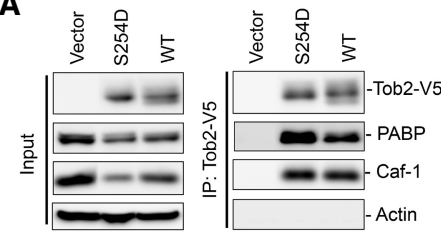

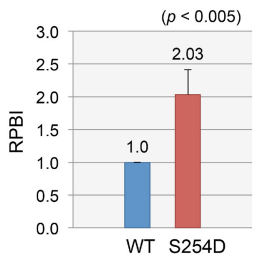

C

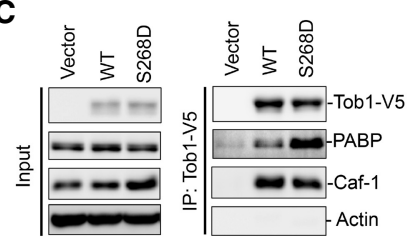

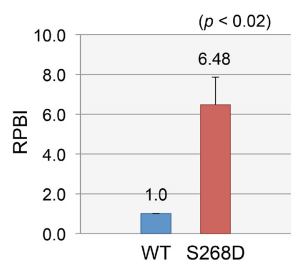

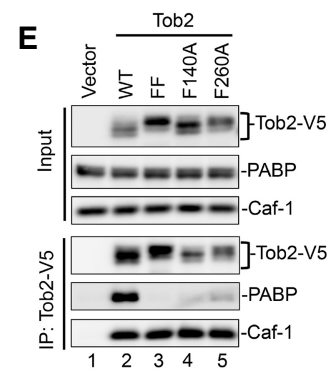

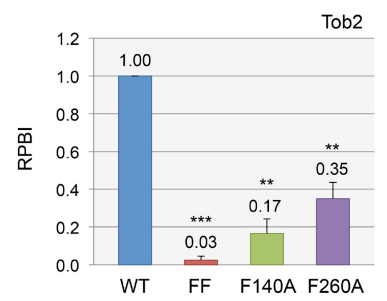

F140A

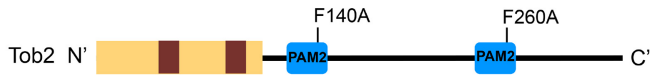

B
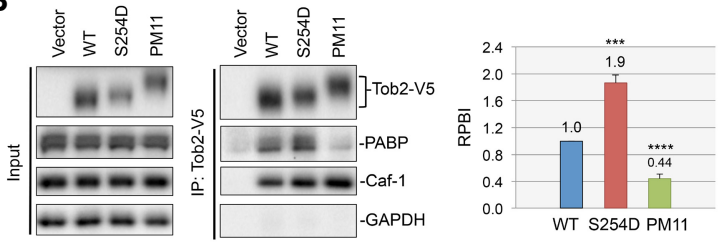

D
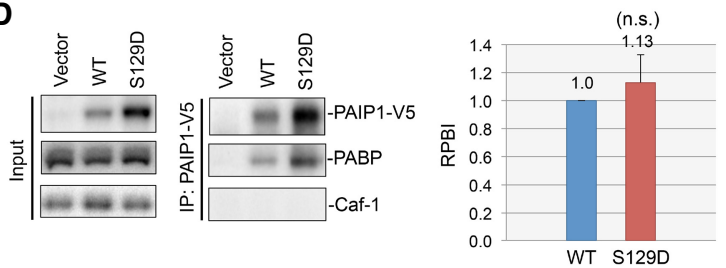

$\mathbf{F}$
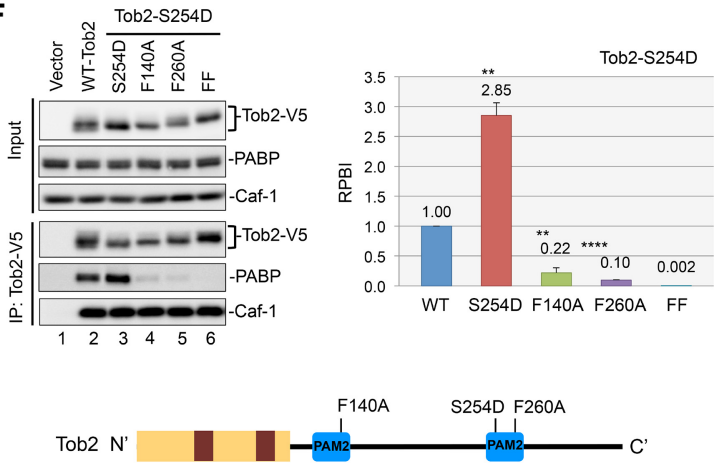

FIGURE 2. Effects of different mutations in the Tob2 IDR on Tob2-PABP interaction. (A) Co-IP western blot analysis showing that phosphomimetic mutation of the serine at the fourth position of the second PAM2 motif of Tob2 (S254D) enhances Tob2 interaction with PABP but has little effect on the Tob2-Caf1 interaction. Transfection with empty vector and western blot probed for actin served as negative controls. Bar graph shows the RPBI values for the relative PABP pulled down. The RPBI for wild type (WT) Tob2-PABP interaction was set as 1. All data represent the normalized mean $\pm S D(n=3)$. (B) Co-IP western blot analysis showing that a Tob2 mutant with phosphomimetic changes of 11 ser/thr sites in the IDR (PM11) weaken the interaction between Tob2 and PABP. Transfection with empty vector and western blot probed for GAPDH served as negative controls. Bar graph shows the RPBI value for the relative PABP pulled down. The RPBI for WT Tob2-PABP interaction was set as 1. All data

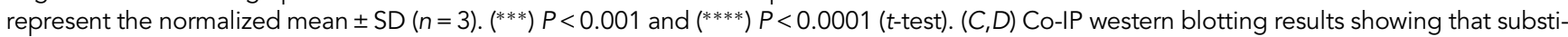
tution of aspartate for the serine at the fourth position of the second PAM2 motif in Tob1 (S268D) greatly enhances Tob1 interaction with PABP, whereas a similar phosphomimetic substitution in the sole PAM2 motif of PAIP1 (S129D) has little effect. Transfection with empty vector and western blot probed for actin (C) or Caf1 (D) served as negative controls. Bar graphs show the RPBI values for the relative PABP pulled down normalized to Tob1 or PAIP1. The RPBI for WT Tob2-PABP interaction was set as 1 . All data represent the normalized mean \pm SD $(n=2)$. $P$ values were obtained from $t$-tests. n.s., $P>0.05$, not significant in $t$-test. $(E, F)$ Co-IP western blotting results showing that the two PAM2 motifs in Tob2 cooperate to expand the range of PABP-interaction strengths. Mutation of the highly conserved phenylalanine in the first (F140A) or second PAM2 motif (F260A) of Tob2 WT (E) or S254D mutant (F) greatly reduces their interactions with PABP. Double mutation (F140A/F260A; FF) of Tob2 WT (E) or Tob2-S254D (F) knocked out Tob2's ability to interact with PABP. The interaction of Tob2 with Caf1 was not affected. A schematic diagram of the arrangement of Tob2 domains and the F140A and F260A mutations is shown below panels $E$ and $F$. Transfection with empty vector served as a negative control. Bar graphs show the RPBI values for the relative PABP pulled down. The RPBI for WT Tob2-PABP interaction was set as 1. All data represent the normalized mean $\pm \mathrm{SD}(n=2)$ except that Tob2-S254D (FF) mutant in panel $F$ was tested only once. $\left({ }^{* *}\right) P<0.01$ and $(* * *) P<$ 0.001 (t-test). Cell extracts for IP experiments were prepared from U2OS cells transiently transfected with plasmids encoding the indicated proteins.

create the Tob2-PM12 mutant. This mutant was overexpressed in U2OS cells and the Tob2-PABP interactions were analyzed by co-IP western blot experiments (Fig. 3). The results showed that the amount of PABP pulled down by the PM12 mutant was much less than that pulled down by S254D but was more than that pulled down by PM11 (Fig. 3A). Similar results were obtained when CAJNK1 was coexpressed with Tob2-S254D mutant (Fig.
3B). The amount of PABP pulled down by Tob2-S254D mutant in the presence of CA-JNK1 was less than that in the absence of CA-JNK1 (Fig. 3B; compare lanes 3,4) but more than the amount of PABP pulled down by WT Tob2 in the presence of CA-JNK1 (Fig. 3B; compare lanes 2,4). In contrast, none of these manipulations affected the Tob2-Caf1 interaction. The data not only corroborate our finding that JNK-induced phosphorylation of Tob2 at 

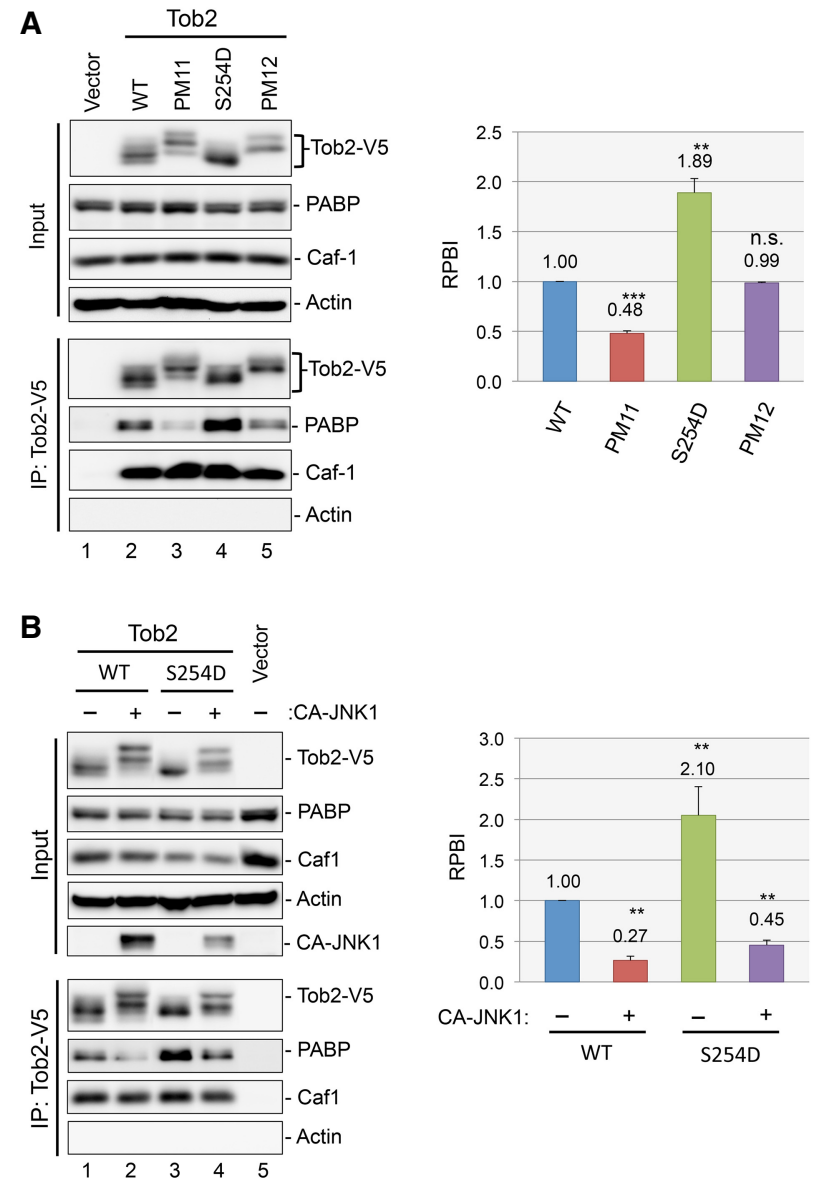

FIGURE 3. Effects of JNK-induced phosphorylation and the corresponding phosphomimetic mutations on the interaction of Tob2 WT or S254D mutant with PABP. (A) Co-IP western blotting results showing that simultaneous phosphomimetic mutation at 11 ser/thr sites in the IDR to mimic JNK-induced hyper-phosphorylation of the Tob2 WT (PM11) or the Tob2-S254D mutant (PM12) weakened Tob2 interactions with PABP but not with Caf1. (B) Co-IP western blotting results showing that ectopic expression of the constitutively active JNK1 isoform (CA-JNK1) increased phosphorylation of both Tob2 WT and S254D mutant and diminished their interactions with PABP. The Tob2 interactions with Caf1 were not affected. Transfection with empty vector and western blot probed for actin served as negative controls. Bar graphs show the RPBI values for the relative PABP pulled. The RPBI for WT Tob2-PABP interaction was set as 1. All data represent the normalized mean $\pm \mathrm{SD}(n=2)$. ( $\left.{ }^{* *}\right) P<0.01$, ( $\left.{ }^{* * *}\right) P<0.001$ and n.s. $(P>0.05$; not statistically significant by $t$-test). Cell extracts for IP experiments were prepared from U2OS cells transiently transfected with plasmids encoding the indicated proteins.

multiple sites in the IDR down-regulated Tob2-PABP interaction but also corroborate the positive effect of JNK-independent phosphorylation of Tob2 S254 on the Tob2-PABP interaction. Moreover, combination of the two distinct modes of Tob2 phosphorylation elicits combined effects on the Tob2-PABP interaction (Fig. 3). These results indicate that the interplay between JNK-induced and JNK-independent phosphorylation modulates Tob2's PABP-binding activity.

\section{The two distinct modes of Tob2 phosphorylation affect the deadenylation-enhancing function of Tob2}

Interaction between Tob2 and PABP is required for Tob2's deadenylation-enhancing function (Ezzeddine et al. 2007, 2012). Given that Tob2-S254D mutation increases the interaction of Tob2 with PABP (Fig. 2A), we performed time-course experiments using the Tet-off driven transcription pulse-chase approach and northern blot analysis (Xu et al. 1998) to assess the S254D mutant's effects on deadenylation of a newly synthesized population of stable $\beta$-globin mRNA driven by the Tet-off promoter. This reporter mRNA population is fairly homogenous in poly(A) tail length. The results (Fig. 4A,B) show that WT Tob2 accelerates deadenylation of $\beta$-globin mRNAs but has little effect on the decay of the deadenylated RNA body, consistent with previous observations (Ezzeddine et al. 2007, 2012). The half-life of $\beta$-globin mRNA in cells expressing WT Tob2 is similar to that in control (vector only) cells

A
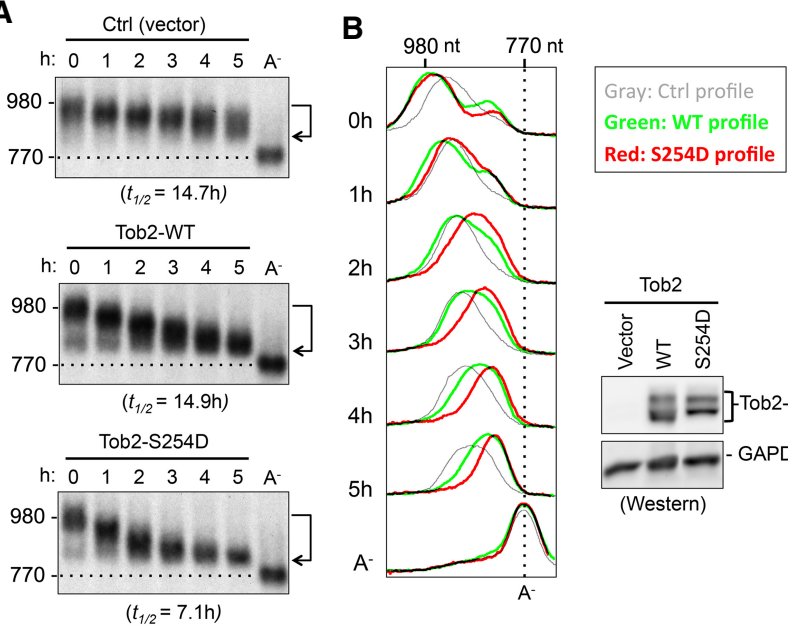

C

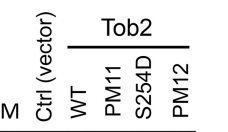

D
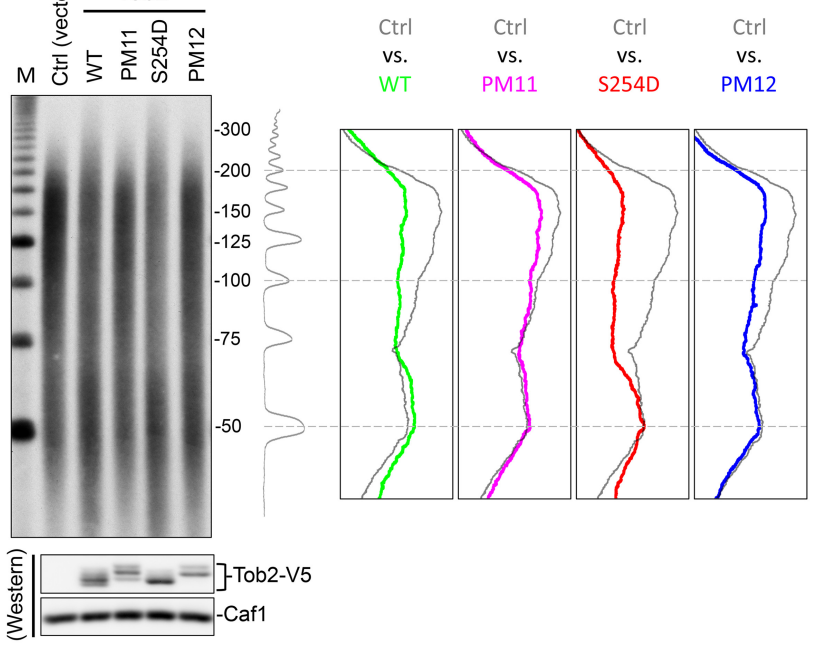

FIGURE 4. (Legend on next page) 
(Fig. $4 \mathrm{~A}, \mathrm{t}_{1 / 2}=\sim 15 \mathrm{~h}$ ). On the other hand, Tob2-S254D expression enhances not only the deadenylation but also the degradation of $\beta$-globin mRNA (Fig. $4 \mathrm{~A}, t_{1 / 2}=\sim 7 \mathrm{~h}$ ).

We then checked the effects of Tob2-S254D and Tob2PM11 mutants on global deadenylation by poly(A) sizedistribution profiling (PASDP) analyses (Huang et al. 2013; Chen et al. 2017) of the entire steady-state cytoplasmic mRNA populations (Fig. 4C,D). A typical poly(A) size distribution profile exhibits two broad peaks, which result from the biphasic nature of deadenylation mediated by two distinct deadenylase complexes, that is, Pan2-Pan3 and Ccr4-Not complexes, respectively (Fig. 4C,D; Huang et al. 2013; Chen et al. 2017). The results show that expression of either WT Tob2 or Tob2-S254D decreased the amount of mRNAs with longer $3^{\prime}$ poly(A) tails and hence the first peak of the profile (Fig. 4C,D). It appears that both WT Tob2 and Tob2-S254D proteins are able to promote shortening of the poly $(A)$ tails all the way through the end of the second phase without going through the Pan2Pan3 mediated first phase. This is consistent with our observations that both WT Tob2 and Tob2-S254D enhance deadenylation of individual reporter mRNAs (Fig. 4A,B). Moreover, consistent with our observation that S254D promotes the deadenylation-enhancing function of WT Tob2 (Fig. 4A,B), the amount of mRNAs with longer poly(A) tails in the presence of Tob2-S254D mutant was less than that in the presence of the WT Tob2 (Fig. 4C,D). When Tob2-

FIGURE 4. Phosphomimetic mutation at S254 of Tob2 further enhances Tob2's ability to promote mRNA deadenylation. (A) Northern blot and time-course experiment results showing the accelerating effects of ectopic expression of Tob2 WT or S254D mutant protein on deadenylation of $\beta$-globin mRNA. Poly(A)- RNA samples $\left(A^{-}\right)$were prepared with oligo(dT) and RNase $H$ treatment. The autorads of the gels were scanned for densitometric analysis of each band using ImageJ software. RNA half-lives $\left(t_{1 / 2}\right)$ in hours $(h)$ were determined by least-square analysis of semilogarithmic plots of normalized mRNA concentration as a function of time. (B) Comparisons of the $\beta$ globin poly $(A)$ shortening profiles in the presence of Tob2 WT or S254D mutant with the profile in control (Ctrl) cells. The autorads of the gels in panel A were scanned for densitometric analysis of each lane using ImageJ software. Western blot showing levels of ectopically expressed Tob2 WT and S254D mutant proteins. GAPDH served as a loading control. (C) (Upper) Denaturing gel showing changes in poly (A) size distribution of the entire mRNA population in control cells, cells ectopically expressing Tob2 protein, or cells ectopically expressing Tob2's mutant derivatives as indicated. Lane M: size markers as labeled to the right of the gel in nucleotide (nt). (Lower) Western blot showing levels of ectopically expressed Tob2 protein and its mutant derivatives. Caf1 served as a loading control. (D) The poly(A) size distribution profiles of the gel in panel $C$ were obtained by densitometric analysis of each lane using ImageJ software. Note that a typical poly (A) size distribution profile (Ctrl) exhibits two peaks at $\sim 150 \mathrm{nt}$ and $\sim 50 \mathrm{nt}$ as a result of the biphasic deadenylation mediated by two different deadenylase complexes (i.e., Pan2-Pan3 and Ccr4-Not complexes), respectively. Total cytoplasmic RNA samples and cell extracts were prepared from U2OS cells transiently transfected with plasmids encoding the indicated proteins.
PM11 mutant was overexpressed, the accumulation of mRNAs with longer poly(A) tails is more than that of WT Tob2 (Fig. 4C,D). Thus, the PM11 mutation, which reduces the ability of Tob2 to interact with PABP (Fig. 2B), compromises the deadenylation-promoting function of Tob2 (Fig. $4 C, D)$. Moreover, a combination of the negative and positive effects caused by respective PM11 and S254D mutations was observed when Tob2-PM12 was overexpressed, resulting in the amount of mRNAs with longer poly(A) tails similar to that of WT Tob2 (Fig. 4C,D). It is worth noting that both WT Tob2 and PM12 mutant exhibit similar strength of PABP binding (Fig. 3A). Thus, the effects of Tob2, Tob2S254D, Tob2-PM11, and Tob2-PM12 proteins on global deadenylation are in parallel with their effects on Tob2PABP interaction. Collectively, our data indicate that the deadenylation-enhancing function of Tob2 can be modulated through the interplay between two distinct ways of regulating its phosphorylation, which elicit opposite effects on Tob2's PABP-binding activity.

\section{CDK-cyclin complexes are involved in the phosphorylation of Tob2 at S254}

An approach combining Kinase Substrate Predictor (version 2.0) in PhosphoNet (http://www.phosphonet.ca/ kinasepredictor.aspx) and the in vitro kinase assay was used to pinpoint kinase candidates for phosphorylation of Tob2 at Ser254. We used a S254A Tob2 peptide for a "non-phosphorylatable 254" control (i.e., a control for background kinase activity). A list of the top 48 candidate kinases most likely to target the S254 was generated (Supplemental Table S2) from 500 kinases scored in the in silico analysis using Kinase Substrate Predictor. Out of the 48 recombinant kinases tested, 16 produced significant (i.e., $>1000$ CPM) phosphorylation of a WT peptide, with more than 50\% change from control (i.e., CFC > 50\%) (Table 1). The top 9 kinase candidates, with the most robust phosphorylation and CFC $>90 \%$, are all cyclin-dependent kinase (CDK-cyclin) complexes. The top five were CDK1cyclinA2, CDK2-cyclinA2, CDK2-cyclinA1, CDK2-cyclinE1, and CDK1-cyclinA1. This is of particular interest because the minimal threshold model of cell cycle control postulates that either CDK1 or CDK2 bound to cyclinA is sufficient to control all stages of interphase (Hochegger et al. 2008).

We then performed a co-IP experiment followed by mass spec analysis to see if any kinases were associated with WT Tob2 or Tob2-S254D proteins. We first filtered out proteins whose levels in the pull-down pool of the negative control account for over $20 \%$ of those in either the WT or S254D Tob2-V5 pull-down pools. We thus identified 86 proteins associated with both WT Tob2 and Tob2-S254D proteins (Supplemental Table S3), including two CDKs (CDK1 and CDK4). This observation complements our results from the in vitro kinase assay (Table 1), strongly 
TABLE 1. Candidate kinases for Tob2 phosphorylation at S254

\begin{tabular}{lccr}
\hline Kinase ID & WT (CPM) & Control (CPM) & CFC \\
\hline CDK1-cyclinA2 & 158,638 & 11,723 & $93 \%$ \\
CDK2-cyclinA2 & 121,836 & 5296 & $96 \%$ \\
CDK2-cyclinA1 & 88,871 & 3858 & $96 \%$ \\
CDK2-cyclinE1 & 85,549 & 3170 & $96 \%$ \\
CDK1-cyclinA1 & 60,960 & 5138 & $92 \%$ \\
CDK3-cyclinE1 & 56,104 & 1655 & $97 \%$ \\
CDK5-p25 & 49,147 & 3885 & $92 \%$ \\
CDK5-p35 & 41,594 & 2154 & $95 \%$ \\
CDK16-cyclinY & 20,124 & 1227 & $94 \%$ \\
ERK2 & 10,344 & 564 & $95 \%$ \\
P38 delta & 8882 & 1152 & $87 \%$ \\
NLK & 4365 & 1938 & $56 \%$ \\
ERK1 & 2845 & 546 & $81 \%$ \\
P38 gamma & 2454 & 498 & $80 \%$ \\
p38 beta & 1607 & 354 & $78 \%$ \\
CDK1-cyclinB1 & 1504 & 298 & $80 \%$ \\
\hline Candidate kinases for Tob2 phosphorylation at S254 were identified by \\
in vitro kinase assay (Supplemental Table S2). A pair of 12-a.a. peptides \\
(a WT and a "non-phosphorylatable 254" control) encompassing S254 \\
residue were synthesized. For the "non-phosphorylatable 254" control \\
peptide, an alanine instead of a serine was synthesized at position corre- \\
sponding to WT S254. This "non-phosphorylatable 254" peptide was \\
used as a control for background phosphorylation by each kinase tested. \\
Kinases displaying more than 1000 counts per minute (CPM) from phos- \\
phorylating a WT peptide and a percentage of change from control \\
(CFC) >50\% in terms of phosphorylation activity are listed here. \\
\end{tabular}

suggesting that Tob2 S254 phosphorylation is likely catalyzed by various CDK-cyclin complexes. Consistently, it was previously reported that CDK2 and CDK 4 are found to be immuno-precipitated along with Tob2 via Caf1 pulldown (Ikematsu et al. 1999). Mass spec analysis also detected two distinct phosphatase catalytic subunits, PPP2CA and PPP3CA (Supplemental Table S3). Taken together, these observations strongly support the notion that several different CDK-cyclin complexes are involved in the phosphorylation of Tob2 at S254.

\section{Transcriptome-wide effects of Tob2 S254 phosphorylation on mRNA turnover}

To investigate the effect of the S254D phosphomimetic mutation on mRNA decay at the transcriptome level, we adapted metabolic labeling RNA-IP sequencing protocols, which combine bromouridine (BrU) pulsing and BrU-RNAIP with high-depth RNA-sequencing (Imamachi et al. 2014; Paulsen et al. 2014), and performed a global mRNA halflife profiling analysis. The methodology does not involve transcription inhibitors, which can have profound and varied side-effects, so disturbances in cell physiology are minimized. We also established U2OS double-stable lines expressing the tTA transcription factor to support induc- tion of WT Tob2 (served as a control for overexpression of Tob2 protein per se), Tob2-S254D mutant, or an empty vector (served as a negative control) expression driven by the Tet-off promoter in the absence of doxycycline. Cells with or without induction were labeled briefly with $\mathrm{BrU}$, followed by variable lengths of uridine chase and extraction of cytoplasmic RNA for subsequent analyses (Fig. 5A).

Using the BrU-RNA samples for high-depth RNA-seq followed by decay rate measurements, we were able to calculate half-lives (Chen et al. 2018) for more than 3400 different transcripts that followed strong first-order decay kinetics under both uninduced and induced conditions for the expression of vector only, WT Tob2, and Tob2S254D (Supplemental Table S4). Cumulative fraction plots show significantly shorter half-lives for the majority of mRNAs across the transcriptome when Tob2-S254D expression was induced (Fig. 5B, $P=2.2 \times 10^{-16}, t$-test). In contrast, WT Tob2 overexpression had a very modest effect on mRNA stability at the transcriptome level (Fig. $5 B, P=0.02168$, t-test). No significant RNA stability change across the transcriptome was observed in control cells (Fig. 5B, $P=0.8268$, t-test). Western blot analysis shows that the WT Tob2 and Tob2-S254D proteins are induced to a similar level (Fig. 5C), indicating that the profound mRNA destabilization by S254D mutant at the transcriptome level (Fig. 5B) is not due to doxycycline induction or the effect of overexpression per se. Combined scatter and density plots of the data further show that Tob2-S254D expression decreased the halflives of both stable and unstable transcripts (Fig. 5D).

In a biological repeat experiment using Tob2-S254D expressing double-stable cell line, we were able to calculate half-lives for more than 3500 different transcripts under both induced and uninduced conditions (Supplemental Table S4, S254D [R2]). The results of the cumulative fraction plot and combined scatter and density plot for the second replicate (Supplemental Fig. S5A,B) are fully consistent with those from the first replicate (Fig. $5 B, D)$. RT-qPCR validation results of three transcripts with different stabilities (Supplemental Fig. S5C) are consistent with those obtained from the transcriptome data. Collectively, the results with the phosphomimetic mutant support the notion that Tob2 phosphorylation at S254 elicits profound destabilization of mRNA across the transcriptome.

\section{S254D enhances Tob2's anti-proliferation effect}

Previous studies reported that compromising the deadenylation-enhancing activity of Tob2 results in a reduction of its ability to suppress proliferation (Miyasaka et al. 2008; Mauxion et al. 2009; Doidge et al. 2012; Ezzeddine et al. 2012). Given the profound enhancing effect of the Tob2-S254D phosphomimetic mutation on mRNA 
A
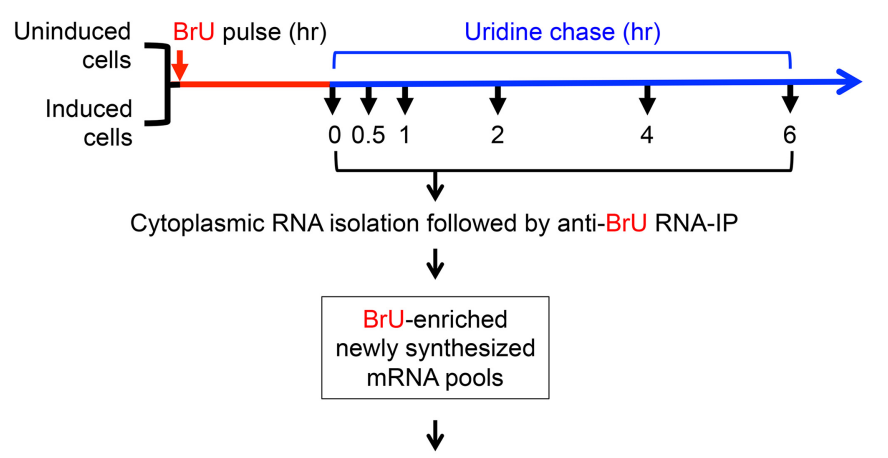

cDNA library construction followed by RNA-seq $\downarrow$

mRNA half-life $\left(t_{1 / 2}\right)$ calculation and bioinformatics analysis of global mRNA turnover

B
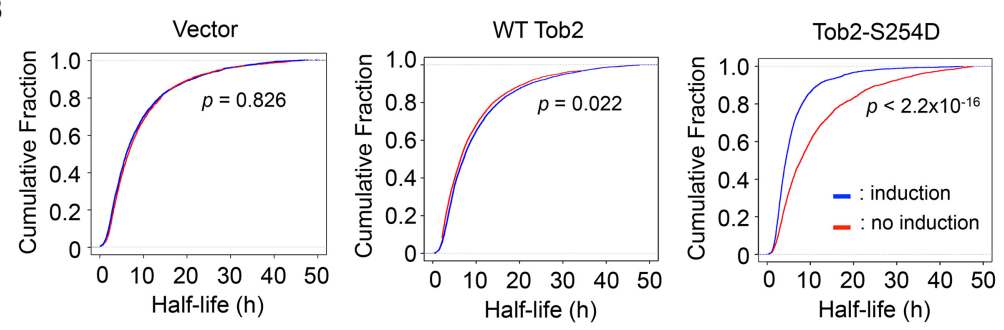

C
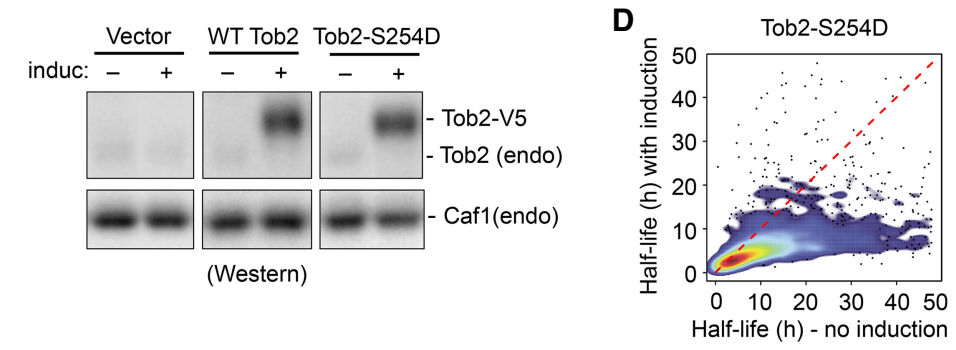

FIGURE 5. Tob2-S254D elicits profound destabilization of mRNA across the transcriptome. (A) Outline of the workflow for bromouridine $(\mathrm{BrU})$ metabolic labeling and transcriptomebased RNA-seq analyses of mRNA decay rates. (B) Cumulative fraction plots showing the distribution of mRNA half-lives of the qualified transcripts exhibiting strong first order decay kinetics with (blue line) and without (red line) induction of empty vector, WT Tob2 or S254D expression (Supplemental Table S4). The $P$ values were calculated by $t$-test. (C) Western blot analysis showing induced WT Tob2 or Tob2-S254D and corresponding endogenous Tob2 proteins, with endogenous Caf1 serving as a loading control. (D) Combined scatter and frequency plot analysis of the half-lives of 3490 transcripts exhibiting strong first order decay kinetics with ( $y$-axis) and without ( $x$-axis) induction of Tob2-S254D expression. Red: most dense; dark blue: least dense. Transcripts with unchanged stability fall on or near the diagonal, dashed red line. Cell extracts and total cytoplasmic RNA samples were prepared from doublestable U2OS cells whose expression of V5-tagged WT Tob2, Tob2-S254D, or vector only is controlled by the Tet-off promoter (see Materials and Methods for details).

deadenylation and decay (Figs. 4, 5B,D), we assessed its effect on Tob2's anti-proliferation function. From the transcripts found in both biological replicates of Tob-S254D data sets (Supplemental Table S5), we identified 1295 transcripts whose half-lives were reduced in both replicates by at least 1.3-fold when the expression of TobS254D was induced. Using the DAVID Bioinformatics Resource to perform KEGG pathways analysis, we found that the top twelve hits were mostly related to cell proliferation and cancer, including Ribosome biogenesis, Transcription mis-regulation in cancer, Signaling pathways regulating pluripotency of stem cells, Bladder cancer, Hippo signaling pathway, Cell cycle, and Pathways in cancer (Supplemental Table S6). We also looked for enriched Gene Ontology (GO) terms of these transcripts. Among the top 10 functional categories, most associated $\mathrm{GO}$ terms were related to regulation of transcription. Importantly, cell cycle is ranked the fourth with 33 genes listed as being affected (Supplemental Table S7). The results of these analyses indicate that many cell cycle, cell growth and cancer related mRNAs are destabilized by Tob2 with the phosphomimetic mutation at S254. They also provide a transcriptomic view of Tob2-affected genes, a view which is fully consistent with Tob proteins being categorized as anti-proliferative (Matsuda et al. 2001; Mauxion et al. 2009; Winkler 2010).

We then performed cell growth assays using the double-stable U2OS cell lines that support expression of WT Tob2, Tob2-S254D, or an empty vector driven by the Tet-off promoter. The results show that Tob2S254D expression significantly suppressed cell growth and exerted a stronger inhibitory effect than did WT Tob2 (Fig. 6A). To corroborate this result, we carried out a clonogenic assay to determine the effect of expressing Tob2-S254D on suppressing U2OS cell survival and proliferation to large colonies. The results (Fig. 6B,C) show that Tob2S254D exhibited much stronger inhibition of colony formation than WT Tob2 did. Collectively, we conclude that the S254D phosphomimetic mutation enhances Tob2's anti-proliferation effect.

\section{DISCUSSION}

Evidence has accumulated during the past decade to support the notion that global modulation of mRNA turnover plays an essential role in cellular homeostasis by 
A

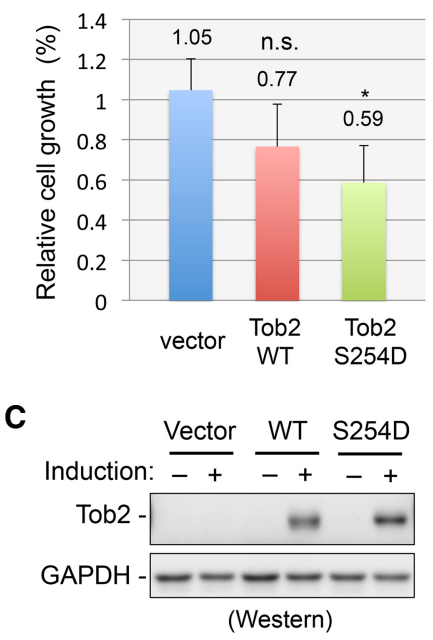

B

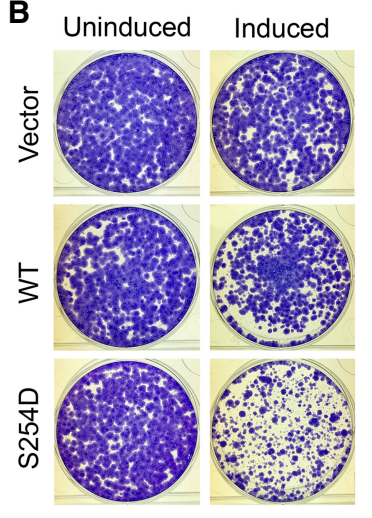

(crystal violet staining)

FIGURE 6. Effects of expression of Tob2 WT or Tob2-S254D mutant on cell proliferation. (A) Cell growth assay of control U2OS cells and cells expressing Tob2 WT or the Tob2-S254D mutant. Results shown represent three biological repeats, each consisting of eight technical repeats. All data in bar graph represent the normalized mean $\pm \mathrm{SD}(n=3) .\left(^{*}\right) P<0.05$ and n.s. (not statistically significant; $P>0.05$ ) by $t$-test. $(B)$ Clonogenic assay of colony forming abilities of control U2OS cells and cells induced to express Tob2 WT or the Tob2-S254D mutant. (Left) Colonies visualized by crystal violet staining after $12 \mathrm{~d}$ of growth under uninduced (+tetracycline) or induced (-tetracycline) conditions. (Right) Phase-contrast images of colonies taken prior to crystal violet staining. Red bar: $250 \mu \mathrm{m}$. (C) Western blot analysis of Tob2 protein expression, with GAPDH as a loading control. Quantitation of the western blot results from three repeats indicates that the slight difference of WT Tob2 versus S254D mutant protein levels normalized to GAPDH is not statistically significant ( $n=3 ; P=0.50$; $t$-test).

reprogramming the transcriptome in response to diverse biological and physiological stimuli (Kawai et al. 2004; Gruber et al. 2014; Chávez et al. 2016; Sharma et al. 2016; Chen and Shyu 2017; Chen et al. 2017). Abnormal mRNA turnover activities can lead to tumorigenesis, chronic inflammation and cardiovascular diseases (Anderson 2010; Goodarzi et al. 2014; Griseri and Pagès 2014; Faraji et al. 2016; Gray and Gray 2017), and an aberrant transcriptome may be an underlying driver of these pathologies. Yet, for mammalian cells it remains largely unknown how global mRNA turnover is modulated to reshape the transcriptome and what underlying mechanisms and trans-acting factors are involved. In this study, we have used directed and transcriptome-based approaches to assess whether and how Tob2, an anti-proliferative factor capable of simultaneously interacting with PABP and Caf1 deadenylase, promotes global mRNA deadenylation and decay to reprogram the transcriptome.

Our previous results indicated that the carboxy-terminal intrinsically disordered region (IDR) of Tob2 can be reversibly phosphorylated at multiple ser/thr sites, directly modulating Tob2's interaction with PABP (Huang et al. 2013). Tob2 hyper-phosphorylation decreased its PABP binding in cells, whereas in vitro dephosphorylation of Tob2 increased its interaction with PABP (Huang et al. 2013). Results in the present study demonstrate the involvement

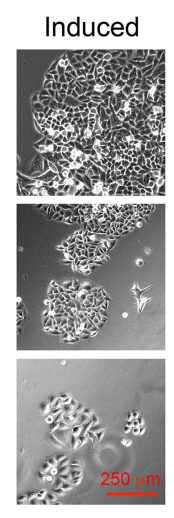

(close-up view; phase contrast) of JNK in Tob2 hyper-phosphorylation. We found that JNK activation increases Tob2 phosphorylation, decreasing its interaction with PABP (Fig. 1A,B; Supplemental Fig. S2). In contrast, JNK inhibition can diminish the hyper-phosphorylation level of Tob2 induced by calyculin A, a general phosphatase inhibitor (Supplemental Fig. S1). These manipulations of Tob2 phosphorylation had little effect on Tob2's interaction with Caf1. Our mass-spec based mapping results have localized the phosphorylation sites induced by JNK1 to the IDR of Tob2 (Fig. 1C; Supplemental Table S1). Phosphomimetic mutations at 11 of these sites (PM11 mutant) markedly decreases Tob2-PABP interaction (Fig. 2B), an effect similar to that observed in the phosphomimetic mutant created previously based on in silico analysis (Supplemental Fig. S6; Huang et al. 2013). Mutating only one or two of the 11 sites either modestly reduces Tob2PABP interaction or has no effect (Supplemental Fig. S3), suggesting that phosphorylating multiple ser/thr sites in the IRD of Tob2 is critical to achieve significant reduction in Tob2-PABP interaction. These data also provide direct evidence to support our previous hypothesis that phosphorylation at the IDR of PAM2-containing proteins (e.g., Tob, Pan3, and GW182) modulates their interactions with PABP (Huang et al. 2013). Collectively, these findings demonstrate that activation of JNK signaling leads to hyper-phosphorylation of Tob2, significantly weakening its interaction with PABP.

The present results also revealed a contrasting instance where phosphorylation of Tob2 actually up-regulates its interaction with PABP. This involves S254 at the fourth position of Tob2's second PAM2 motif (Supplemental Fig. S4), which is the most frequently detected site of phosphorylation in human Tob2 (Fig. 1C; Supplemental Table S1). S254 in Tob2 was also found to be phosphorylated in mammalian cells by four different deep phosphoproteomics studies (Pflieger et al. 2008; Franz-Wachtel et al. 2012; Mertins et al. 2013, 2016). Two lines of evidence support the notion that phosphorylation of Tob2 S254 is JNK-independent. First, inhibition of residual JNK activity in proliferating cells by overexpressing a dominant-negative mutant of JNK1 has little effect on Tob2-PABP interaction (Supplemental Fig. S2B). Second, none of the JNK isoforms was scored in our in vitro kinase assay (Table 1). Notably, in addition to enhancing Tob2-PABP interaction 
and Tob2's ability to accelerate deadenylation, phosphomimetic mutation at S254 (S254D) also promotes the decay of mRNA (Figs. 2-5). The results from poly(A) sizedistribution profiling assay (Fig. 4B,D) and mRNA turnover analysis across the transcriptome (Fig. 5) show that the S254D phosphomimetic mutation greatly enhances Tob2's ability to promote global mRNA deadenylation and decay. The majority of the transcripts, whether inherently stable or labile, undergo accelerated decay in the presence of the Tob2-S254D mutant (Fig. 5D). We propose that Tob2 promotes global mRNA turnover in a phosphorylation-dependent manner, which represents a novel way of cytoplasmic mRNA clearance to help reprogram the transcriptome in mammalian somatic cells during their growth and differentiation. Phosphorylation at the fourth position of the second PAM2 motif of Tob1 in vivo was also found by a deep phosphoproteomics approach (Sharma et al. 2014). Our present finding that phosphomimetic changes at these particular positions of Tob1 and Tob2 enhance their interactions with PABP (Fig. 2A,C) supports a phosphorylation-dependent regulation of Tob proteins' PABP-binding activities, and thus their effects on global mRNA turnover.

A more detailed regulatory context of Tob2 phosphorylation at S254 is provided by our findings from mass-spec and in vitro kinase analyses that suggest connections to PP2B and PP2C phosphatases and CDK-cyclin complexes, particularly CDK1, CDK2, and CDK4 (Table 1; Supplemental Table S2). A previous study also reported that CDK2 and CDK4 were coimmunoprecipitated along with Tob2 by Caf1 pulldown (lkematsu et al. 1999). One possibility is that a CDK-cyclin complex, indirectly brought to Tob2 by Caf1, phosphorylates S254 in Tob2 to regulate deadenylation. The CDK-cyclin complexes are key players in regulating cell cycle progression (Taulés et al. 1998; Hochegger et al. 2008; Chenette 2010; Enserink and Kolodner 2010). The developing picture at this point has Tob2 subjected to dynamic, reversible phosphorylation at S254 as cells go through different phases of cell cycle during proliferation.

Tob proteins are unique among the large family of PAM2-containing PABP-interacting proteins in having two separate copies of the PAM2 motif (Supplemental Fig. S4; Albrecht and Lengauer 2004; Huang et al. 2013). Our results show that both PAM2 motifs must be present for maximal interaction of Tob2 with PABP (Fig. 2E) and for the enhancing effect of the S254D mutation on PABP-binding (Fig. 2F). It is possible that having this second PAM2 motif gives Tob2 a wider range of PABP interaction strengths than in members with only one PAM2 motif, allowing a finer tuning of global mRNA deadenylation and decay for transcriptome reprogramming.

Our co-IP/mass spec results show that both Caf1 and $\mathrm{PABP}$ are in the list of Tob2-associated proteins (Table 2; CNOT7, CNOT8, and PABP). Consistent with the co-IP/ western blot analysis (Fig. 2A), much more PABP associates with Tob2-S254D than with WT Tob2 (Table 2). Moreover, 10 out of 11 members of the human Ccr4-Not complex were among the top $20 \%$ of most frequently detected proteins in the Tob2-associated proteins list (Table 2; Supplemental Table S3). It is worth noting that the co-IP/ mass spec results show the levels of the detected members of Ccr4-Not complex are generally higher in the Tob2-S254D pull-down than in the WT Tob2 pull-down (Table 2), while co-IP western blot analysis shows that changes in Tob2 phosphorylation level have little effect on the ability of Tob2 to pull down Caf1 (Fig. 1A). One possibility is that the phosphorylation of S254 helps stabilize the interaction of Tob2 with the Ccr4-Not complex, which could contribute to Tob2's ability to recruit the entire Ccr4-Not complex and thus further enhances deadenylation. These results (Table 2) further support the notion that Tob2 promotes global mRNA turnover in a phosphorylation-dependent manner.

The present results shed new light on the recruitment model for Tob2-mediated mRNA turnover we proposed previously (Ezzeddine et al. 2007, 2012). In the updated model, upon phosphorylation of S254, possibly by a CDK-cyclin complex, the carboxy-terminal IDR region of Tob2 adopts a structure that better orients the two PAM2 motifs for favorable PABP interactions (Fig. 7A). The

TABLE 2. PABP and components of the Ccr4-Not complex pulled down by WT Tob2 or by Tob2-S254D

\begin{tabular}{|c|c|c|c|}
\hline \multirow[b]{2}{*}{ Human component (M.W. in kDa) } & \multicolumn{2}{|c|}{$\begin{array}{l}\text { Detected } \\
\text { peptide } \\
\text { counts }^{a}\end{array}$} & \multirow{2}{*}{$\begin{array}{c}\text { Ratio } \\
\text { S254D/WT }\end{array}$} \\
\hline & WT & $\mathrm{S} 245 \mathrm{D}^{\mathrm{b}}$ & \\
\hline CNOT1 (266.8) & 360 & 481 & 1.34 \\
\hline CNOT2 (59.7) & 200 & 291 & 1.45 \\
\hline CNOT3 (81.8) & 76 & 121 & 1.59 \\
\hline CNOT6/Ccr4a (63.3) & 25 & 33 & 1.32 \\
\hline CNOT6L/Ccr4b (63) & 52 & 90 & 1.73 \\
\hline CNOT7/Caf1a (32.7) & 68 & 45 & 0.66 \\
\hline CNOT8/Caf1b (33.5) & 30 & 81 & 2.71 \\
\hline CNOT9 (33.6) & 53 & 99 & 1.86 \\
\hline CNOT10 (82.3) & 86 & 142 & 1.65 \\
\hline CNOT11 (55.2) & 73 & 80 & 1.09 \\
\hline $\mathrm{PABP}^{\mathrm{C}}(70.6)$ & 150 & 403 & 2.69 \\
\hline Tob2 (36.6) & 90 & 90 & 1 \\
\hline \multicolumn{4}{|c|}{$\begin{array}{l}\text { PABP and Ccr4-Not complex components pulled down by WT Tob2 or } \\
\text { by Tob2-S254D are listed here. } \\
\text { aTotal ion current of peptide fragments from the indicated proteins (back- } \\
\text { ground subtracted). } \\
\text { bTotal ion current of peptides from the indicated protein normalized to } \\
\text { that of WT Tob2 and multiplied by } 90 \text {. } \\
\text { cIncludes peptides from PABPC1 and PABPC4 proteins, the two major } \\
\text { cytoplasmic forms of PABP. }\end{array}$} \\
\hline
\end{tabular}


S254 phosphorylation step has an important mechanistic implication in deadenylation and decay-it allows Tob2 to bring the Caf1 and Ccr4 deadenylases in the Ccr4Not complex to the close proximity of the $3^{\prime}$ poly(A)PABP complex for accelerated removal of the poly $(A)$ tail in a wide range of transcripts, thereby enhancing the global deadenylation and also subsequent decay of the RNA body (Fig. 7B). One might also envisage that when cells experience a stress, activated JNKs rapidly phosphorylate multiple ser/thr sites in the IDR, weakening the Tob2PABP interaction and leading to a pause of Tob2-mediated global mRNA turnover.

Increasing evidence shows that the Ccr4-Not complex is important in cytoplasmic mRNA turnover (Collart 2016; Bresson and Tollervey 2018; Webster et al. 2018; Yi et al. 2018). Our present results reveal a novel mechanism for signal-dependent recruitment of the Ccr4-Not complex by Tob2 to the 3' poly(A)-PABP complex of mRNAs, promoting global mRNA deadenylation and decay, clearing cytoplasmic mRNAs, and eliciting transcriptome reprogramming to regulate cell growth. This paradigm may be

A

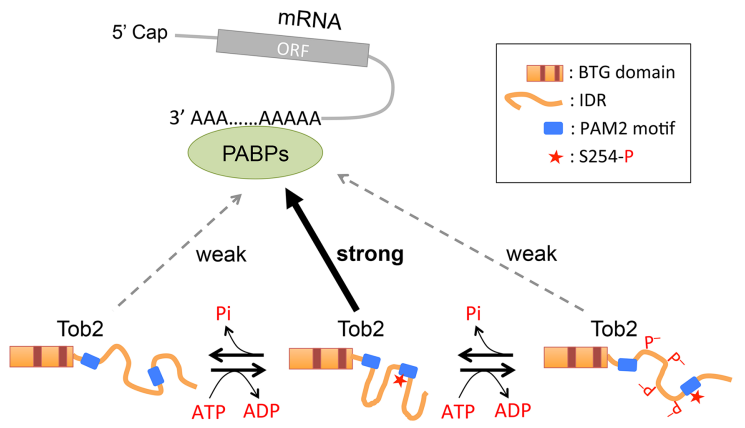

B

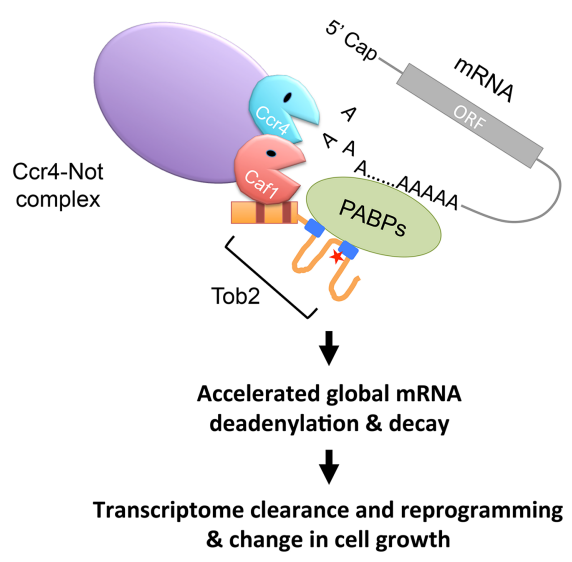

FIGURE 7. A hypothetical model for phosphorylation-dependent regulation of Tob2 function. Refer to the Discussion for details. $(A)$ Three different patterns of Tob2 phosphorylation that weaken or strengthen the Tob2-PABP interaction. (B) Tob2 phosphorylation at S254 proposed to favor alignment of the two PAM2 motifs, strengthening interactions with PABP and optimally positioning the $\mathrm{Ccr} 4-\mathrm{Not}$ complex and the $3^{\prime}$ poly(A)-PABP complex to facilitate poly(A) removal. For simplicity, some known phosphorylation sites in the IDR are omitted from the cartoons. a useful guide to future studies of how signaling-dependent changes in the interactions between PABP and its many binding partners achieve global modulations of mRNA fate in response to diverse cellular and environmental stimuli.

\section{MATERIALS AND METHODS}

\section{Plasmid constructs}

The plasmids pTet-BBB (Xu et al. 1998), Tob1-V5, Tob2-V5, Tob2-FF (Ezzeddine et al. 2007), MS2-Tob2-V5 (Ezzeddine et al. 2012), Paip1-V5 (Craig et al. 1998), and Caf1-V5 (Zheng et al. 2008) were created as described previously. The plasmids pcDNA-FLAG-MKK7B2-JNK1a1 coding for the constitutively active JNK1 isoform and pcDNA-FLAG-MKK7B2-JNK1a1(APF) coding for the dominant-negative JNK1 isoform were gifts from Roger J. Davis (Addgene plasmids \# 19726 and \# 19730). We used the In-Fusion cloning kit (Clontech) and followed the manufacturer's protocol to create Tob2-V5 plasmid derivatives carrying the S117D, S199D, S222D, T224E/S226D, S232D, T244E, S251D, S254D, PM11, PM12, F140A, or F260A mutation, Tob2-S254D-V5 plasmid derivatives carrying the F140A, F260A, or F140A/F260A (FF) mutation, plasmid Tob1-S268D-V5, plasmid Paip1-S129D-V5, pLVX-Tob2-V5, and pLVX-Tob2S254D-V5. The pLVX-tight-puro tetracycline-inducible lentivirus expression vector (Clontech) was used to construct the pLVXTob2-V5 and pLVX-Tob2-S254D-V5 plasmids. All resulting plasmids were confirmed by DNA-sequencing.

\section{Cell culture, transfection, immunoprecipitation, and western blot analysis}

All cells used were cultured at $37^{\circ} \mathrm{C}$ with $5 \% \mathrm{CO}_{2}$. U2OS and $293 \mathrm{~T}$ cells were cultured in high glucose DMEM (Invitrogen) containing 10\% fetal bovine serum (Invitrogen) and 1× penicillin/streptomycin/glutamine (Gibco). For culturing NIH3T3-B2A2 cells, a stable cell line harboring the tetracycline-responsive transcription factor tTA (Xu et al. 1998), the medium above was supplemented with $500 \mathrm{ng} / \mathrm{mL}$ tetracycline (Sigma-Aldrich). For culturing U2OS stable cell lines harboring the tetracycline-responsive transcription factor tTA (see below), $200 \mathrm{ng} / \mathrm{mL}$ doxycycline (Sigma-Aldrich) was included in the medium. The sources for kinase inhibitors were: Calbiochem (Akt inhibitor IV, Roscovitine, SL0101), Cell Signaling (Y-27632), and Selleckchem (SB216763, SB203580, SP600125, Rapamycin, U0126, LY294002). Calyculin A was purchased from Cell Signaling. Transfections, immunoprecipitation and western blot analyses were performed as described previously with modifications (Huang et al. 2013; Chen et al. 2017). Briefly, cells were lysed at $4^{\circ} \mathrm{C}$ in co-IP lysis buffer (50 mM Tris pH 7.4, 150 $\mathrm{mM} \mathrm{NaCl}, 0.4 \%$ NP-40, 1 mM EGTA, and 10\% glycerol) with protease and phosphatase inhibitors $(2 \mathrm{mM}$ sodium orthovanadate, $2 \mathrm{mM}$ sodium pyrophosphate, $10 \mathrm{mM}$ sodium fluoride, $1 \mathrm{mM}$ phenylmethylsulfonyl fluoride, $1 \times$ complete Protease inhibitor from Roche, $1 \times$ phosphatase inhibitor cocktail 3 from SigmaAldrich). RNase A (Sigma-Aldrich) was added to lysate at final concentration of $1 \mu \mathrm{g} / \mu \mathrm{L}$. Lysates were incubated at $4^{\circ} \mathrm{C}$ for $1 \mathrm{~h}$ with rotation to digest RNA. One-tenth of the lysate was saved 
for input protein level examination, and the rest of the lysate was incubated with anti-V5 agarose affinity beads (Sigma-Aldrich) at $4^{\circ} \mathrm{C}$ with rotation for $2 \mathrm{~h}$ to pull down V5-tagged protein. The beads were subject to five washes with the lysis buffer and one wash with phosphate-buffered saline (PBS). The protein samples were resolved on a $7.5 \%$ or $10 \%$ SDS-PAGE and then transferred to Immobilon-P or PVDF membranes (Millipore). Different antibodies used for the western blot analysis were diluted in the ratio as follows: 1:1000 for goat anti-Tob2 antibody (Santa Cruz Biotechnology); 1:20,000 for rabbit anti-PABPC1 antibody (a gift from R.E. Lloyd, Baylor College of Medicine); 1:20,000 for rabbit anti-Caf-1 antibody (Yamashita et al. 2005); 1:50,000 for mouse anti-V5-HRP conjugated antibody (Invitrogen); 1:20,000 for rabbit anti-GAPDH-HRP conjugated antibody (Santa Cruz Biotechnology); 1:1000 for rabbit anti-JNK antibody and rabbit anti-phospho-JNK (Thr183/Tyr185) antibody (Cell Signaling); 1:2000 for rabbit anti-FLAG antibody (Sigma-Aldrich); 1:10,000 for anti-beta-actin HRP-conjugated monoclonal antibody (Santa Cruz Biotechnology); and 1:4000 for anti-rabbit secondary antibodies (Bethyl). The membranes were probed with SuperSignal West Pico chemiluminescent solution (Thermo Fisher Scientific). Western blot densitometric images were acquired and analyzed using either GeneGnome (Syngene) and GeneSnap software or Bio-Rad ChemiDoc Imaging and Image Lab software.

\section{Creating U2OS stable cell lines}

We adopted the Lenti-X Tet-off Advanced Inducible Expression System (Clontech). To create stable U2OS tet-off line expressing tTA, we first used lipofectamine 2000 to transfect 293T cells with the following plasmids to produce viral particles: pLVX-Tetoff advance (Clontech), psPAX2 (Addgene plasmid \# 12260; a gift from Didier Trono), and pMD2.G (Addgene plasmid \# 12259; a gift from Didier Trono). The medium was replaced $24 \mathrm{~h}$ after transfection, and virus-containing media were collected 8-32 h later. For viral infection, U2OS cells were seeded in a 12-well plate and cultured overnight. The medium was then replaced with virus-containing medium and culture continued for $24 \mathrm{~h}$ to allow infection. The infected cells were further cultured for $10 \mathrm{~d}$ while undergoing G418 (400 $\mu \mathrm{g} / \mathrm{mL}$; Thermo Fisher Scientific) and doxycycline (50 ng/mL; Sigma-Aldrich) double selection. Fifty surviving cells were seeded in a 10-cm dish to grow for another $10 \mathrm{~d}$ in selection medium. Individual colonies were identified, amplified and characterized for proper doxycycline responsiveness as described previously (Xu et al. 1998). U2OS subclone 29 (U2OS-29) was used for creating U2OS double-stable lines that support WT Tob2-V5, Tob2-S254D-V5 mutant, or vector (control) expression in a doxycycline-dependent manner. To create these double-stable lines, 293T cells were transfected with the following plasmids to produce viral particles: pLVXtight-puro (Clontech), psPAX2, pMD2.G and either pLVX-Tob2V5 or pLVX-Tob2-S254D-V5 plasmids. The medium was replaced $24 \mathrm{~h}$ after transfection and the virus-containing media were collected 24-48 h later. For viral infection, U2OS-29 cells were seeded in six-well plates in medium containing $200 \mathrm{ng} / \mathrm{mL}$ doxycycline. After overnight incubation, the medium was replaced with virus-containing medium and culture continued for 6-8 $\mathrm{h}$ before the virus-containing medium was replaced with fresh medium containing $200 \mathrm{ng} / \mathrm{mL}$ doxycycline. After overnight incu- bation, the cells were replated in medium containing doxycycline ( $200 \mathrm{ng} / \mathrm{mL}$ ) and puromycin $(4 \mu \mathrm{g} / \mathrm{mL})$ and cultured for $48 \mathrm{~h}$. The medium was then replaced with fresh medium containing doxycycline $(200 \mathrm{ng} / \mathrm{mL})$ and a lower level of puromycin $(500 \mathrm{ng} / \mathrm{mL})$ and cultured for another $48 \mathrm{~h}$. Surviving cells from individual plates were pooled, allowed to grow to the desired density, and stored as double-stable lines. Individual double-stable lines were verified for inducible expression of WT Tob2-V5 or Tob2-S254D$\mathrm{V} 5$ in the absence of doxycycline by western blot analysis.

\section{Northern blot analysis and poly(A) size-distribution profiling assay}

Time course experiments using the tTA-expressing NIH3T3 stable cell line (B2A2) (Xu et al. 1998) were performed as described previously (Chen et al. 2008). Briefly, cells were transfected with vector, Tob2-V5 or Tob2-S254D-V5 expressing plasmid, along with the pTet-BBB reporter plasmid, and were cultured in medium containing tetracycline $(30 \mathrm{ng} / \mathrm{mL})$ for $42-48 \mathrm{~h}$. This was followed by a $2 \mathrm{~h}$ incubation in fresh medium without tetracycline to allow transient expression of the reporter mRNAs driven by the Tet-off promoter. Tetracycline was added back to the medium at a final concentration of $500 \mathrm{ng} / \mathrm{mL}$ to stop transcription from the Tet-off promoter, and cells were harvested at different time points for RNA extraction. Total cytoplasmic RNA was isolated using the RNeasy Mini kit (Qiagen). Northern blot analysis (Chen et al. 2008) and poly(A) size distribution profile analysis (Huang et al. 2013; Chen et al. 2017) were performed as described previously. The RNA body of rabbit $\beta$-globin mRNA used as a reporter mRNA in the northern blot analysis has a size of $770 \mathrm{nt}$ in length plus about $210 \mathrm{nt}$ of a poly(A) tail. The experiments were performed twice with reproducible results. Autoradiograms were scanned and the resulting digital images analyzed for poly $(A)$ size distribution profiles using ImageJ software (NIH).

\section{Real-time quantitative RT-PCR analysis}

Reverse transcription was performed using 100-200 ng of BrU-enriched RNA sample in a $20 \mu \mathrm{L}$ reverse transcription reaction containing MultiScribe reverse transcriptase (Applied Biosystems). The reaction was incubated at $25^{\circ} \mathrm{C}$ for $10 \mathrm{~min}$ followed by an incubation at $37^{\circ} \mathrm{C}$ for $120 \mathrm{~min}$ and then at $85^{\circ} \mathrm{C}$ for $5 \mathrm{~min}$. After reverse transcription, $\mathrm{PCR}$ reactions were performed using the C1000 touch CFX96 real time system (Bio-Rad) according to the manufacturer's protocol. Each $20 \mu \mathrm{L}$ reaction contains $1 \times$ TaqMan Gene Expression Assay (Applied Biosystems), which has premixed TaqMan MGB probes and primers, 1× TaqMan Universal Master Mixll (Applied Biosystems), which has DNA polymerase, dNTP, salt and buffer, and $2 \mu \mathrm{L}$ of cDNA from reverse transcription. Half-lives of mRNAs were determined by least squares regression of each time point data set to a one-exponential decay equation (Chen et al. 2008).

\section{Bromouridine metabolic labeling of RNA and RNA-immunoprecipitation}

Bromouridine ( $\mathrm{BrU}$ ) metabolic labeling of RNA and RNA-immunoprecipitation (RNA-IP) followed a protocol modified from Paulsen 
et al. (2013) and Imamachi et al. (2014). Briefly, $7.5 \times 10^{6}$ U2OS double-stable cells were seeded per $15-\mathrm{cm}$ dish, with two dishes for each time point. After overnight incubation, cells were pulselabeled for $2 \mathrm{~h}$ with $10 \mathrm{mM} \mathrm{BrU}$ ( $\mathrm{TCl}$ Chemicals) and then cultured in medium containing $20 \mathrm{mM}$ uridine (Sigma-Aldrich). Cells for the $0 \mathrm{~h}$ time point were harvested immediately, whereas cells for the other time points were incubated at $37^{\circ} \mathrm{C}$ with $5 \% \mathrm{CO}_{2}$ for an additional $0.5,1,2,4$, or $6 \mathrm{~h}$ before harvesting. In each case, cytoplasmic RNA was extracted using the RNeasy Mini Kit (Qiagen) following the manufacturer's protocol. For BrU-RNA-IP, $20 \mu \mathrm{g}$ of anti-BrU mAb (BD Pharmingen) and $250 \mu \mathrm{L}$ of Dynabeads Protein G slurry (Invitrogen) were first mixed and incubated at $4^{\circ} \mathrm{C}$ overnight with gentle agitation. RNA sample (100 $\mu \mathrm{g}$ ) was added to the antibody-Dynabeads mixture and agitated at $4^{\circ} \mathrm{C}$ for $4 \mathrm{~h}$ before the BrU-RNA was eluted from the antibodyDynabeads complex using the RNeasy Mini Kit clean-up protocol. The final eluted BrU-RNA was in $50 \mu \mathrm{L}$ of RNase-free $d_{d H_{2}} \mathrm{O}$ and the concentration was measured using Quant-iT RiboGreen RNA Assay Kit (Thermo Fisher Scientific). The BrU-RNA integrity and lack of any significant rRNAs contamination were confirmed using the Agilent Bioanalyzer 2100 and Agilent RNA 6000 Pico Kit reagents.

\section{RNA-sequencing and decay rate calculation across the transcriptome}

cDNA libraries were prepared from the BrU-RNA time-course samples using the TruSeq Stranded Total RNA Kit (Illumina). An aliquot of each of the libraries was analyzed on an Agilent DNA 1000 chip (Agilent) to assess the size distribution. RNA sequencing (75 nt paired-end) was conducted on an Illumina HiSeq 4000 (Sequencing and Microarray facility, MD Anderson Cancer Center). Subsequent RNA-seq data processing and RNA half-life calculations were done by TACGenomics. The resulting 75 nt paired-end RNA-seq reads were first mapped to the latest UCSC transcript set using Bowtie 2 version 2.1.0 (Langmead and Salzberg 2012) and the gene expression level was estimated using RSEM v1.2.15 (Li 2011). We only considered genes with transcript expression levels $\geq 10$ TPM (Transcripts Per Million) in high-depth RNA-sequencing. The expression level of each transcript was normalized to that of the $\beta$ actin (ACTB_NM_001101) transcript. RNA decay rates across the transcriptome were calculated as described previously (Chen et al. 2017) using a custom $R$ script (Chen et al. 2018). Transcripts whose half-life estimates could not be accurately determined, as indicated by a high residual value $(>0.5)$ for the root-mean-square deviation (RMSD) between experimental and fitted values, were filtered out. Supplemental Table S4 lists the calculated half-lives of the final group of transcripts under each treatment. The raw RNA-sequencing data have been deposited in the Gene Expression Omnibus under accession numbers GSE137170 and GSE149684.

\section{In vitro kinase assay}

In vitro kinase assays were perform by the Kinexus Bioinformatics. Two 12-a.a. peptides synthesized by Kinexus for the assays: Tob2-S254 WT peptide (APQSQLSPNAKK) was used as a phosphorylatable substrate and Tob $2-S 254 A$ (APQSQLAPNAKK) was used as a non-phosphorylatable control for background kinase activities. Purified recombinant kinase proteins were tested. Briefly, all kinase assays were performed at room temperature for 20-40 min depending on the kinase in a final reaction volume of $25 \mu \mathrm{L}$ according to the following assay reaction recipe: Component 1 includes $5 \mu \mathrm{L}$ of diluted active protein kinase (10-50 nM final protein conc in the assay); Component 2 includes $5 \mu \mathrm{L}$ of assay solution of test substrate; Component 3 includes $10 \mu \mathrm{L}$ of kinase assay buffer; Component 4 includes $5 \mu \mathrm{L}$ of [gamma- ${ }^{33} \mathrm{P}$ ] ATP $(250 \mu \mathrm{M}$ stock solution, $0.8 \mu \mathrm{Ci})$. The kinase assay was initiated by the addition of [gamma- $\left.{ }^{33} \mathrm{P}\right]$ ATP and was terminated by spotting $10 \mu \mathrm{L}$ of the reaction mixture onto a multiscreen phosphocellulose P81 plate. The multiscreen phosphocellulose P81 plate was washed three times for $15 \mathrm{~min}$ each in a $1 \%$ phosphoric acid solution. The radioactivity on the P81 plate was counted in the presence of scintillation fluid in a Trilux scintillation counter.

\section{Mass spectrometry}

Cells expressing Tob2-V5 or Tob2-S254D-V5 protein were lysed in co-IP lysis buffer (50 mM Tris pH 7.4, $15 \mathrm{mM} \mathrm{NaCl}, 1 \% \mathrm{NP}-40$, $1 \mathrm{mM}$ EGTA, 10\% glycerol, and 2\% BSA) containing protease and phosphatase inhibitors (2 $\mathrm{mM}$ sodium orthovanadate, $2 \mathrm{mM}$ sodium pyrophosphate, $10 \mathrm{mM}$ sodium fluoride, $1 \mathrm{mM}$ phenylmethylsulfonyl fluoride, $1 \times$ Complete Protease Inhibitor [Roche], and 1× Phosphatase Inhibitor Cocktail 3 [SigmaAldrich]). RNA was digested with RNase A (Sigma-Aldrich). After centrifugation to remove cellular debris, each lysate was adjusted to $0.5 \mathrm{mg} / \mathrm{mL}$ protein and precleared with anti-HA agarose beads (Sigma-Aldrich). Anti-V5 agarose beads (Sigma-Aldrich) were preblocked with the co-IP lysis buffer overnight before adding to precleared lysate for immuno-precipitation. Interactions between the anti-V5 beads and Tob2-V5 or Tob2-S254D-V5 proteins were disrupted with $\mathrm{V} 5$ peptide elution buffer $(0.4 \mathrm{mg} / \mathrm{ml}$ V5 peptide [Sigma-Aldrich]) in $25 \mathrm{mM}$ Tris $\mathrm{pH} 7.4,100 \mathrm{mM} \mathrm{NaCl}$, and $0.05 \%$ Triton $\mathrm{X}-100$. The eluted proteins were concentrated with a $10 \mathrm{kDa}$ cut-off centrifugal filter (Amicon) before SDSPAGE electrophoresis. Gel bands containing proteins of interest were excised, digested, and analyzed by microcapillary LC/MS/ MS (Taplin Mass Spectrometry Facility, Harvard Medical School). Peptide sequences and protein identities were determined by matching protein databases with the acquired fragmentation pattern using Sequest software (Thermo Fisher Scientific) (Eng et al. 1994). All databases include a reversed version of all the sequences, and the peptide data were filtered to a $1 \%-2 \%$ false discovery rate. The final group of qualified proteins found to be coimmunoprecipitated in the control, Tob2-V5 or Tob2S254D-V5 samples are listed in Supplemental Table S3.

The MS2-Tob2-V5 fusion protein was used for mass-spec phospho-site mapping. The MS2 tag encoding an RNA-binding domain from MS2 phage increases the molecular mass of Tob2-V5 by $\sim 20 \mathrm{kDa}$ and helps the separation of MS2-Tob2V5 from the IgG heavy-chain during gel electrophoresis, thus simplifying subsequent mass-spec analysis. Two sets of phospho-site assignment scores, Ascore and ModScore (Beausoleil et al. 2006), were used to localize the phosphate(s) present in individual Tob2 peptides (Supplemental Table S1), with the threshold for confident assignment set at $>13$. 


\section{Cell proliferation and clonogenic assays}

Proliferation assays used a CyQUANT Cell Proliferation Kit (Invitrogen) and followed the manufacturer's protocol. For each assay, eight replicate aliquots of $100 \mu \mathrm{L}$ medium containing $1 \times$ $10^{3}$ cells were pipetted on a 96-well plate (Corning). Fluorescence intensities were measured with an Infinite 200 PRO plate reader (Tecan). For clonogenic assay, duplicate aliquots of $2 \times 10^{3}, 5 \times 10^{3}$ or $1 \times 10^{4}$ cells were seeded with $3 \mathrm{~mL}$ of medium in six-well plates. The medium was changed every $4 \mathrm{~d}$ for a period of $12 \mathrm{~d}$ of incubation. On day 12, crystal violet $(0.05 \% \mathrm{w} / \mathrm{v})$ staining was performed and capture of images was done using a Leica DMI 400B inverted light microscope system. Phase-contrast images were captured prior to crystal violet staining.

\section{Statistical analysis}

For western blot analyses, cell growth assays and cumulative fraction plots, all grouped data are presented as mean $\pm \mathrm{SD}$. Student's t-test was used to determine statistical significance between groups. When exact $P$ values are not indicated, they are represented as follows: $\left(^{*}\right) P<0.05,\left(^{* *}\right) P<0.01,(* * *) P<0.001$, $(* * *)) P<0.0001$, (n.s.) $P>0.05$.

\section{SUPPLEMENTAL MATERIAL}

Supplemental material is available for this article.

\section{ACKNOWLEDGMENTS}

We thank R. Kulmacz for critically reading the manuscript, Y. Ho for technical assistance, the Sequencing and Microarray Facility of MD Anderson Cancer Center (Houston, TX) for the RNA-seq service (core grant CA016672 [SMF]), the Taplin Mass Spectrometry Facility at Harvard Medical School for the mass spectrometry service, Kinexus for the in vitro kinase assay service, TACGenomics (Encino, CA) for the service for bioinformatics analysis of RNA-seq data, R.J. Davis (U Mass) for JNK plasmids, and R. E. Lloyd (Baylor College of Medicine) for providing anti-PABPC1 antibody. This work was supported by grants from the National Institutes of Health (National Institute of General Medical Sciences) (RO1 GM046454 and R35 GM127109 to A.-B.S.) and in part by the Houston Endowment, Inc. (to A.-B.S.).

Received October 1, 2019; accepted May 8, 2020.

\section{REFERENCES}

Albrecht M, Lengauer T. 2004. Survey on the PABC recognition motif PAM2. Biochem Biophys Res Commun 316: 129-138. doi:10 .1016/j.bbrc.2004.02.024

Anderson P. 2010. Post-transcriptional regulons coordinate the initiation and resolution of inflammation. Nat Rev Immunol 10: 24-35. doi:10.1038/nri2685

Beausoleil SA, Villén J, Gerber SA, Rush J, Gygi SP. 2006. A probability-based approach for high-throughput protein phosphorylation analysis and site localization. Nat Biotechnol 24: 1285-1292. doi:10.1038/nbt1240
Bresson S, Tollervey D. 2018. Tailing off: PABP and CNOT generate cycles of mRNA deadenylation. Mol Cell 70: 987-988. doi:10 .1016/j.molcel.2018.06.009

Cao D, Parker R. 2001. Computational modeling of eukaryotic mRNA turnover. RNA 7: 1192-1212. doi:10.1017/S1355838201010330

Chávez S, García-Martínez J, Delgado-Ramos L, Pérez-Ortín JE. 2016. The importance of controlling mRNA turnover during cell proliferation. Curr Genet 62: 701-710. doi:10.1007/s00294-016-0594-2

Chen C-YA, Shyu A-B. 2011. Mechanisms of deadenylation-dependent decay. Wiley Interdiscip Rev RNA 2: 167-183. doi:10.1002/ wrna.40

Chen C-YA, Shyu A-B. 2017. Emerging themes in regulation of global mRNA turnover in cis. Trends Biochem Sci 42: 16-27. doi:10 .1016/j.tibs.2016.08.014

Chen CA, Ezzeddine N, Shyu AB. 2008. Messenger RNA half-life measuremments in mammalian cells. Methods Enzymol 448: 335-357. doi:10.1016/S0076-6879(08)02617-7

Chen CA, Zhang Y, Xiang Y, Han L, Shyu AB. 2017. Antagonistic actions of two human Pan3 isoforms on global mRNA turnover. RNA 23: 1404-1418. doi:10.1261/rna.061556.117

Chen CA, Zhang Y, Xiang Y, Han L, Shyu AB. 2018. Corrigendum: Antagonistic actions of two human Pan3 isoforms on global mRNA turnover. RNA 24: 1607-1612. doi:10.1261/rna.068387 .118

Chenette EJ. 2010. A key role for CDK2. Nat Rev Cancer 10: 84. doi:10.1038/nrc2799

Collart MA. 2016. The Ccr4-Not complex is a key regulator of eukaryotic gene expression. Wiley Interdiscip Rev RNA 7: 438-454. doi:10.1002/wrna.1332

Craig AW, Haghighat A, Yu AT, Sonenberg N. 1998. Interaction of polyadenylate-binding protein with the elF4G homologue PAIP enhances translation. Nature (London) 392: 520-523. doi:10.1038/ 33198

Doidge R, Mittal S, Aslam A, Winkler GS. 2012. The anti-proliferative activity of BTG/TOB proteins is mediated via the Caf1a (CNOT7) and Caf1b (CNOT8) deadenylase subunits of the Ccr4-not complex. PLoS One 7: e51331. doi:10.1371/journal.pone.0051331

Du H, Zhao Y, He J, Zhang Y, Xi H, Liu M, Ma J, Wu L. 2016. YTHDF2 destabilizes $\mathrm{m}^{6} \mathrm{~A}$-containing RNA through direct recruitment of the CCR4-NOT deadenylase complex. Nat Commun 7: 12626. doi:10.1038/ncomms12626

Eng JK, McCormack AL, Yates JR. 1994. An approach to correlate tandem mass spectral data of peptides with amino acid sequences in a protein database. J Am Soc Mass Spectrom 5: 976-989. doi:10 .1016/1044-0305(94)80016-2

Enserink JM, Kolodner RD. 2010. An overview of Cdk1-controlled targets and processes. Cell Div 5: 11. doi:10.1186/1747-1028-5-11

Ezzeddine N, Chang T-C, Zhu W, Yamashita A, Chen C-YA, Zhong Z, Yamashita Y, Zheng D, Shyu A-B. 2007. Human TOB, an antiproliferative transcription factor, is a poly(A)-binding protein-dependent positive regulator of cytoplasmic mRNA deadenylation. Mol Cell Biol 27: 7791-7801. doi:10.1128/MCB.01254-07

Ezzeddine N, Chen CA, Shyu A-B. 2012. Evidence providing new insights into TOB-promoted deadenylation and supporting a link between TOB's deadenylation-enhancing and antiproliferative activities. Mol Cell Biol 32: 1089-1098. doi:10.1128/MCB.06370-11

Faraji F, Hu Y, Yang HH, Lee MP, Winkler GS, Hafner M, Hunter KW. 2016. Post-transcriptional control of tumor cell autonomous metastatic potential by CCR4-NOT deadenylase CNOT7. PLoS Genet 12: e1005820. doi:10.1371/journal.pgen.1005820

Franz-Wachtel M, Eisler SA, Krug K, Wahl S, Carpy A, Nordheim A, Pfizenmaier K, Hausser A, Macek B. 2012. Global detection of protein kinase D-dependent phosphorylation events in nocodazoletreated human cells. Mol Cell Proteomics 11: 160-170. doi:10 $.1074 /$ mcp.M111.016014 
Garneau NL, Wilusz J, Wilusz CJ. 2007. The highways and byways of mRNA decay. Nat Rev Mol Cell Biol 8: 113-126. doi:10.1038/ nrm2104

Goodarzi H, Zhang S, Buss CG, Fish L, Tavazoie S, Tavazoie SF. 2014. Metastasis-suppressor transcript destabilization through TARBP2 binding of mRNA hairpins. Nature 513: 256-260. doi:10.1038/ nature13466

Gray GA, Gray NK. 2017. A tail of translational regulation. eLife 6: e29104. doi:10.7554/eLife.29104

Griseri P, Pagès G. 2014. Regulation of the mRNA half-life in breast cancer. World J Clin Oncol 5: 323-334. doi:10.5306/wjco.v5.i3 .323

Gruber AR, Martin G, Müller P, Schmidt A, Gruber AJ, Gumienny R, Mittal N, Jayachandran R, Pieters J, Keller W, et al. 2014. Global $3^{\prime}$ UTR shortening has a limited effect on protein abundance in proliferating $T$ cells. Nat Commun 5: 5465. doi:10.1038/ ncomms 6465

Hochegger H, Takeda S, Hunt T. 2008. Cyclin-dependent kinases and cell cycle transitions: Does one fit all? Nat Rev Mol Cell Biol 9: 910916. doi:10.1038/nrm2510

Hoshino SI. 2012. Mechanism of the initiation of mRNA decay: role of eRF3 family G proteins. Wiley Interdiscip Rev RNA 3: 743-757. doi:10.1002/wrna.1133

Huang K-L, Chadee AB, Chen C-YA, Zhang Y, Shyu A-B. 2013. Phosphorylation at intrinsically disordered regions of PAM2 motif-containing proteins modulates their interactions with PABPC1 and influences mRNA fate. RNA 19: 295-305. doi:10.1261/rna .037317 .112

Ikematsu N, Yoshida Y, Kawamura-Tsuzuku J, Ohsugi M, Onda M, Hirai M, Fujimoto J, Yamamoto T. 1999. Tob2, a novel anti-proliferative Tob/BTG1 family member, associates with a component of the CCR4 transcriptional regulatory complex capable of binding cyclin-dependent kinases. Oncogene 18: 7432-7441. doi:10 .1038/sj.onc. 1203193

Imamachi N, Tani H, Mizutani R, Imamura K, Irie T, Suzuki Y, Akimitsu N. 2014. BRIC-seq: a genome-wide approach for determining RNA stability in mammalian cells. Methods 67: 55-63. doi:10.1016/j.ymeth.2013.07.014

lordanov MS, Pribnow D, Magun JL, Dinh TH, Pearson JA, Chen SL, Magun BE. 1997. Ribotoxic stress response: activation of the stress-activated protein kinase JNK1 by inhibitors of the peptidyl transferase reaction and by sequence-specific RNA damage to the $\alpha$-sarcin/ricin loop in the 28S rRNA. Mol Cell Biol 17: 33733381. doi:10.1128/MCB.17.6.3373

Kawai T, Fan J, Mazan-Mamczarz K, Gorospe M. 2004. Global mRNA stabilization preferentially linked to translational repression during the endoplasmic reticulum stress response. Mol Cell Biol 24: 6773-6787. doi:10.1128/MCB.24.15.6773-6787.2004

Kozlov G, Ménade M, Rosenauer A, Nguyen L, Gehring K. 2010. Molecular determinants of PAM2 recognition by the MLLE domain of poly(A)-binding protein. J Mol Biol 397: 397-407. doi:10.1016/j .jmb.2010.01.032

Langmead B, Salzberg SL. 2012. Fast gapped-read alignment with Bowtie 2. Nat Methods 9: 357. doi:10.1038/nmeth.1923

Lei K, Nimnual A, Zong W-X, Kennedy NJ, Flavell RA, Thompson CB, Bar-Sagi D, Davis RJ. 2002. The Bax subfamily of Bcl2-related proteins is essential for apoptotic signal transduction by c-Jun $\mathrm{NH}_{2-}$ terminal kinase. Mol Cell Biol 22: 4929. doi:10.1128/MCB.22.13 $.4929-4942.2002$

Li B. 2011. RSEM: accurate transcript quantification from RNA-Seq data with or without a reference genome. BMC Bioinformatics 12: 323. doi:10.1186/1471-2105-12-1

Lim J, Lee M, Son A, Chang H, Kim VN. 2016. mTAIL-seq reveals dynamic poly(A) tail regulation in oocyte-to-embryo development. Genes Dev 30: 1671-1682. doi:10.1101/gad.284802.116
Matsuda S, Rouault J-P, Magaud J-P, Berthet C. 2001. In search of a function for the TIS21/PC3/BTG1/TOB family. FEBS Lett 497: 67-72. doi:10.1016/S0014-5793(01)02436-X

Mauxion F, Faux C, Seraphin B. 2008. The BTG2 protein is a general activator of mRNA deadenylation. EMBO J 27: 1039-1048. doi:10 .1038/emboj.2008.43

Mauxion F, Chen CY, Séraphin B, Shyu AB. 2009. BTG/TOB factors impact deadenylases. Trends Biochem Sci 34: 640-647. doi:10 .1016/j.tibs.2009.07.008

Mertins P, Qiao JW, Patel J, Udeshi ND, Clauser KR, Mani DR, Burgess MW, Gillette MA, Jaffe JD, Carr SA. 2013. Integrated proteomic analysis of post-translational modifications by serial enrichment. Nat Methods 10: 634-637. doi:10.1038/ nmeth. 2518

Mertins P, Mani DR, Ruggles KV, Gillette MA, Clauser KR, Wang P, Wang X, Qiao JW, Cao S, Petralia F, et al. 2016. Proteogenomics connects somatic mutations to signalling in breast cancer. Nature 534: 55-62. doi:10.1038/nature18003

Mishima Y, Tomari Y. 2016. Codon usage and $3^{\prime}$ UTR length determine maternal mRNA stability in zebrafish. Mol Cell 61: 874885. doi:10.1016/j.molcel.2016.02.027

Miyasaka T, Morita M, Ito K, Suzuki T, Fukuda H, Takeda S, Inoue J, Semba K, Yamamoto T. 2008. Interaction of antiproliferative protein Tob with the CCR4-NOT deadenylase complex. Cancer Sci 99: 755-761. doi:10.1111/j.1349-7006.2008.00746.x

Morgan M, Much C, DiGiacomo M, Azzi C, Ivanova I, Vitsios DM, Pistolic J, Collier P, Moreira PN, Benes V, et al. 2017. mRNA $3^{\prime}$ uridylation and poly(A) tail length sculpt the mammalian maternal transcriptome. Nature 548: 347. doi:10.1038/ nature23318

Okochi K, Suzuki T, Inoue JI, Matsuda S, Yamamoto T. 2005. Interaction of anti-proliferative protein Tob with poly(A)-binding protein and inducible poly(A)-binding protein: implication of Tob in translational control. Genes Cells 10: 151-163. doi:10.1111/j .1365-2443.2005.00826.x

Osawa M, Hosoda N, Nakanishi T, Uchida N, Kimura T, Imai S, Machiyama A, Katada T, Hoshino S, Shimada I. 2012. Biological role of the two overlapping poly(A)-binding protein interacting motifs 2 (PAM2) of eukaryotic releasing factor eRF3 in mRNA decay. RNA 18: 1957-1967. doi:10.1261/rna.035311.112

Paulsen MT, Veloso A, Prasad J, Bedi K, Ljungman EA, Tsan Y-C, Chang C-W, Tarrier B, Washburn JG, Lyons R, et al. 2013. Coordinated regulation of synthesis and stability of RNA during the acute TNF-induced proinflammatory response. Proc Natl Acad Sci 110: 2240-2245. doi:10.1073/pnas.1219192110

Paulsen MT, Veloso A, Prasad J, Bedi K, Ljungman EA, Magnuson B, Wilson TE, Ljungman M. 2014. Use of Bru-Seq and BruChase-Seq for genome-wide assessment of the synthesis and stability of RNA. Methods 67: 45-54. doi:10.1016/j.ymeth.2013.08.015

Pflieger D, Junger MA, Muller M, Rinner O, Lee H, Gehrig PM, Gstaiger M, Aebersold R. 2008. Quantitative proteomic analysis of protein complexes: concurrent identification of interactors and their state of phosphorylation. Mol Cell Proteomics 7: 326346. doi:10.1074/mcp.M700282-MCP200

Reznik B, Lykke-Andersen J. 2010. Regulated and quality-control mRNA turnover pathways in eukaryotes. Biochem Soc Trans 38: 1506. doi:10.1042/BST0381506

Sharma K, D'Souza Rochelle CJ, Tyanova S, Schaab C, Wiśniewski Jacek R, Cox J, Mann M. 2014. Ultradeep human phosphoproteome reveals a distinct regulatory nature of Tyr and Ser/Thrbased signaling. Cell Rep 8: 1583-1594. doi:10.1016/j.celrep .2014.07.036

Sharma S, Poetz F, Bruer M, Ly-Hartig Thi Bach N, Schott J, Séraphin B, Stoecklin G. 2016. Acetylation-dependent control of 
global poly(A) RNA degradation by CBP/p300 and HDAC1/2. Mol Cell 63: 927-938. doi:10.1016/j.molcel.2016.08.030

Shyu $A B$, Wilkinson MF, van Hoof A. 2008. Messenger RNA regulation: to translate or to degrade. EMBO J 27: 471-481. doi:10 .1038/sj.emboj.7601977

Suganuma M, Fujiki H, Furuya-Suguri H, Yoshizawa S, Yasumoto S, Kato Y, Fusetani N, Sugimura T. 1990. Calyculin A, an inhibitor of protein phosphatases, a potent tumor promoter on CD-1 mouse skin. Cancer Res 50: 3521-3525.

Taulés M, Rius E, Talaya D, López-Girona A, Bachs O, Agell N. 1998. Calmodulin is essential for cyclin-dependent kinase 4 (Cdk4) activity and nuclear accumulation of cyclin D1-Cdk4 during $\mathrm{G}_{1}$. J Biol Chem 273: 33279-33286. doi:10.1074/jbc.273.50.33279

Webster MW, Chen Y-H, Stowell JAW, Alhusaini N, Sweet T, Graveley BR, Coller J, Passmore LA. 2018. mRNA deadenylation is coupled to translation rates by the differential activities of Ccr4-Not nucleases. Mol Cell 70: 1089-1100.e1088. doi:10 .1016/j.molcel.2018.05.033

Weill L, Belloc E, Bava F-A, Mendez R. 2012. Translational control by changes in poly(A) tail length: recycling mRNAs. Nat Struct Mol Biol 19: 577-585. doi:10.1038/nsmb.2311
Winkler GS. 2010. The mammalian anti-proliferative BTG/Tob protein family. J Cell Physiol 222: 66-72. doi:10.1002/jcp.21919

Xie J, Kozlov G, Gehring K. 2014. The "tale" of poly(A) binding protein: the MLLE domain and PAM2-containing proteins. Biochim Biophys Acta 1839: 1062-1068. doi:10.1016/j.bbagrm.2014.08.001

Xu N, Loflin P, Chen C-YA, Shyu A-B. 1998. A broader role for AU-rich element-mediated mRNA turnover revealed by a new transcriptional pulse strategy. Nucleic Acids Res 26: 558-565. doi:10 $.1093 /$ nar/26.2.558

Yamashita A, Chang TC, Yamashita Y, Zhu W, Zhong Z, Chen CY, Shyu AB. 2005. Concerted action of poly(A) nucleases and decapping enzyme in mammalian mRNA turnover. Nat Struct Mol Biol 12: 1054-1063. doi:10.1038/nsmb1016

Yi H, Park J, Ha M, Lim J, Chang H, Kim VN. 2018. PABP cooperates with the CCR4-NOT complex to promote mRNA deadenylation and block precocious decay. Mol Cell 70: 1081-1088.e1085. doi:10.1016/j.molcel.2018.05.009

Zheng D, Ezzeddine N, Chen C-YA, Zhu W, He X, Shyu A-B. 2008 Deadenylation is prerequisite for P-body formation and mRNA decay in mammalian cells. J Cell Biol 182: 89-101. doi:10.1083/jcb 200801196 

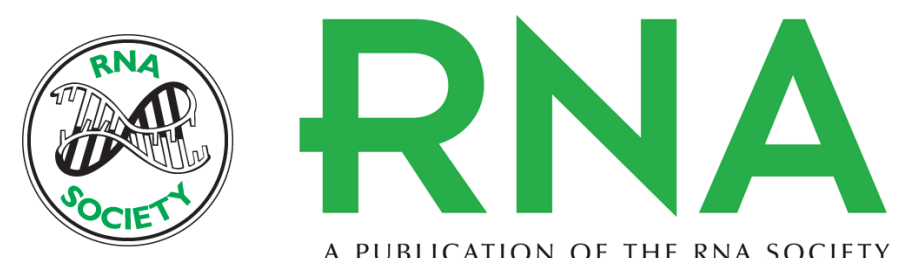

A PUBLICATION OF THE RNA SOCIETY

\section{Tob2 phosphorylation regulates global mRNA turnover to reshape transcriptome and impact cell proliferation}

Chyi-Ying A. Chen, Krista Strouz, Kai-Lieh Huang, et al.

RNA 2020 26: 1143-1159 originally published online May 13, 2020

Access the most recent version at doi:10.1261/rna.073528.119

\section{Supplemental http://rnajournal.cshlp.org/content/suppl/2020/05/13/rna.073528.119.DC1 \\ Material}

References This article cites 66 articles, 18 of which can be accessed free at: http://rnajournal.cshlp.org/content/26/9/1143.full.html\#ref-list-1

Creative This article is distributed exclusively by the RNA Society for the first 12 months after the Commons

License full-issue publication date (see http://rnajournal.cshlp.org/site/misc/terms.xhtml). After 12 months, it is available under a Creative Commons License (Attribution-NonCommercial 4.0 International), as described at http://creativecommons.org/licenses/by-nc/4.0/.

Email Alerting Receive free email alerts when new articles cite this article - sign up in the box at the Service top right corner of the article or click here. 